\title{
Bipolar Cells Specific for Blue Cones in the Macaque Retina
}

\author{
Nobuo Kouyamaa and David W. Marshak \\ Department of Neurobiology and Anatomy, The University of Texas Medical School, Houston, Texas 77025
}

\begin{abstract}
A distinct subpopulation of bipolar cells in macaque monkey retina was labeled with antisera that recognize glycine-extended cholecystokinin precursors. The labeled bipolar cells were found throughout the retina and had dendrites contacting a subpopulation of cone pedicles and axons ramifying in the fifth stratum of the inner plexiform layer. Several lines of evidence indicate that the labeled bipolar cells are a single type despite some variations in their morphology. First, the density of perikarya and their diameters varied continuously as a function of eccentricity. Second, the positions of perikarya within the inner nuclear layer and the level at which the axons branched in the inner plexiform layer were constant at all eccentricities. Bipolar cells with similar morphology have been described previously as "blue cone bipolar cells" (Mariani, 1984b), but there was no direct evidence that this was the case.
\end{abstract}

In this study, we show by light microscopy that labeled bipolar cells have dendrites ending exclusively upon presumptive blue cones labeled by Procion black dye. All blue cones were contacted by labeled bipolar cells, and virtually all bipolar cells contacted blue cones, the only exceptions being in regions where blue cones had been lost. Approximately $\mathbf{2 0} \%$ more labeled bipolar cells than blue cones were found at every eccentricity; thus, connections between blue cones and labeled bipolar cells were not strictly one to one. The mean number of cones presynaptic to each bipolar cell was 1.2, and the mean number of bipolar cells postsynaptic to each cone was 1.8 .

By an electron microscopic study of labeled bipolar cell dendrites, we determined that they became central elements

Received Aug. 30, 1991; revised Oct. 24, 1991; accepted Nov. 4, 1991

We are grateful to Mrs. Lillemor Krosby for technical assistance. We also thank Dr. Tadataka Yamada and Dr. John Del Valle for providing antisera; Dr. Francisco de Monasterio and Dr. Kenneth Wikler for providing their data on the blue cone distribution; Dr. Robert Smith, Dr. Randolph Nudo, and Mr. Keith Patricio for their assistance with computer programs; and Dr. Brian Boycott, Dr. Helga Kolb, and the anonymous reviewers for critical reading of the manuscript. Dr. Daniel Felleman and Dr. Robert Rodieck gave us valuable suggestions and several pairs of monkey eyes. We are grateful to Dr. Jack Crawford and Dr. Ernst Knobil for providing other eyes used in this study. Eyes were also provided by the Tissue Distribution Programs at the Regional Primate Research Centers at the Universities of California (NIH Grant RR 00169) and Washington (NIH Grant RR 00166 ), or purchased from the lexas Primate Center. This work was supported by Grant EY 06472 from the National Eye Institute of the National Institutes of Health, Grant 1945 from the Texas Advanced Research Program to D.W.M., and Postdoctoral Research Fellowship PD89-060 from the Fight for Sight Research Division of National Society to Prevent Blindness to N.K.

Correspondence should be addressed to David W. Marshak, Department of Neurobiology and Anatomy, University of Texas Medical School, P.O. Box 20708, Houston, TX 77225 .

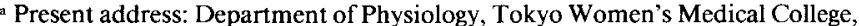
8-1, Kawada-Cho, Shinjuku, Tokyo 162, Japan.

Copyright (C) 1992 Society for Neuroscience 0270-6474/92/121233-20\$05.00/0 of ribbon synapses in blue cones. Some of their ribbon synapses were unusual: in one type, a single, large labeled dendrite was postsynaptic to two or more ribbons, while in the other type, ribbons had two or more central elements. The presence of these invaginating contacts and the axonal terminals in the proximal inner plexiform layer suggest that the labeled bipolar cells depolarize to short-wavelength stimuli and function to relay information from blue cones to the inner plexiform layer. There were also other, unlabeled bipolar cell dendrites that received inputs from blue cones at basal junctions and triad-associated flat contacts, which suggests that there are additional types of bipolar cells conveying information from short-wavelength cones in the primate retina.

In retinas of old world primates, including humans, there are three types of cones that are maximally sensitive to long (red), middle (green), and short (blue) wavelength light. All three types of cones are similar in the polarity and kinetics of their light responses (Schnapf et al., 1988), and they are thought to use the neurotransmitter glutamate (Massey, 1990). The red and green cones are indistinguishable except by their absorption spectra, but the blue cones are different from the other cones in their morphology and spatial distribution (Marc and Spcrling, 1977; Marc, 1982; McCrane et al., 1983; de Monasterio et al., 1985; Ahnelt et al., 1987, 1990; Szél et al., 1988). There are no known differences between the bipolar cells that contact red and green cones (Kolb and Lipetz, 1991; Wässle and Boycott, 1991). There is a growing body of evidence, however, that there are morphologically distinct bipolar cells that contact blue cones exclusively (Famiglietti, 1981; Mariani, 1984a,b; de Monasterio and Mariani, 1985; Rodieck, 1988). The evidence for blue coneselective bipolar cells in the primate retina is indirect since these cells have not been studied by intracellular recording and dye injection. Using the Golgi method, Mariani (1984b) identified one type of bipolar cell in the macaque retina whose dendrites make selective, ribbon contacts with a subpopulation of cones that had the same sparse but nonrandom distribution as the blue cones (Marc and Sperling, 1977; de Monasterio et al., 1981; Williams et al., $1981 \mathrm{a}, \mathrm{b})$. $\Lambda$ xons of this bipolar cell terminated in the most proximal or fifth stratum of the inner plexiform layer (IPL). A second type of bipolar cell that contacted blue cones was decribed briefly by de Monasterio and Mariani (1985) using intraocular Lucifer yellow injection.

Six additional morphological subtypes of bipolar cells are known in the primate retina-one rod bipolar cell and five cone bipolar cells, all clearly different from the first type of blue cone bipolar cell (for review, see Mariani, 1984a; Rodieck, 1988; Kaplan et al., 1990; Wässle and Boycott, 1991). Invaginating and flat midget bipolar cells usually connect with a single cone 
(Polyak, 1941; Boycott and Dowling, 1969; Kolb et al., 1969; Kolb, 1970), but it is not possible to distinguish their chromatic type morphologically. Giant bistratified bipolar cells with dendritic fields large enough to contact many cones (Mariani, 1983) and invaginating and flat diffuse bipolar cells that contact several cones have also been described in macaque retinas (Polyak, 1941; Mariani, 1981, 1984a). There have been no double label studies to determine whether any of these bipolar cells contact blue cones, but the latter three types are thought to contact all the cones in their dendritic fields.

There is indirect physiological evidence that blue cone bipolar cells respond to light by depolarizing (reviewed by Zrenner and Gouras, 1981). The retinal ganglion cells that respond preferentially to short-wavelength stimuli have a far greater percentage of ON responses than OFF responses (reviewed by de Monasterio, 1984; Kolb and Lipetz, 1991). In addition, the b-wave, the component of the electroretinogram thought to reflect bipolar cell activity, is observed at both the onset and offset of long- and middle-wavelength stimuli, but a response is observed only at the onset of short-wavelength stimuli (Evers and Gouras, 1986). This response is blocked by 2-amino-4-phosphonobutyric acid (APB), a glutamate agonist that hyperpolarizes the ON-center bipolar cells. On the other hand, a recent study (Smith et al., 1989) showing that intraocular injections of APB had no selective effects on the sensitivity of macaques to short-wavelength stimuli suggests that there may be other types of bipolar cells that contact blue cones.

Recently, a subpopulation of bipolar cells morphologically similar to Mariani's blue cone bipolar cells was labeled in macaque retina by an immunocytochemical technique using antisera that recognize glycine-extended cholecystokinin (CCK) precursors (Marshak et al., 1990). The present study describes the morphology of these bipolar cells and demonstrates that they receive input exclusively from blue cones by simultaneously labeling the blue cone population with Procion black (McCrane et al., 1983). We analyzed the regional variations in their morphology and their density distribution, and we calculated convergence and divergence factors at their synapses with blue cones in peripheral retina. From an EM investigation of labeled bipolar contacts with blue cones, we described some unusual features of their synaptic contacts within the blue cone pedicles.

Some of these findings have been reported in abstract form previously (Kouyama and Marshak, 1989).

\section{Materials and Methods}

\section{Retinas}

Eyes were obtained from nine Macaca mulatta, four $M$. fascicularis, and seven $M$. nemestrina. They were donated by other investigators at the Texas Medical Center or else purchased from the Texas Primate Center, the Regional Primate Research Center at the University of Washington, or the California Regional Primate Research Center. The eyes were enucleated immediately after death by an overdose of pentobarbital. After removing the anterior half of the eye and as much vitreous humor as possible, the posterior half was fixed by immersion. A few eyes were fixed by vascular perfusion and postfixed by immersion.

\section{Antisera}

Four rabbit antisera against the synthetic peptide G6-gly that recognize glycine-extended forms of CCK precursors were kindly provided by Dr. T. Yamada and Dr. J. Del Valle (University of Michigan), including $821206 \# 37$, R6B16, R5B16, and R8B15. The specificity of these antisera has been tested in the primate retina previously (Marshak et al., 1990).

\section{Immunolabeling protocols for light microscopy}

Whole retinas. For light microscopic (LM) studies, the eyes were hemisected and fixed by immersion overnight, usually in PAF fixative: $0.1 \%$ picric acid, $4 \%$ paraformaldehyde in $0.1 \mathrm{~m}$ sodium phosphate buffer (PB), $\mathrm{pH}$ 7.2. Other retinas were fixed in one of following fixatives: $4 \%$ paraformaldehyde in $\mathrm{PB}, \mathrm{pH} 7.2$; PAF with $0.05 \%$ glutaraldehyde; or $0.1 \mathrm{M}$ lysinc, $0.01 \mathrm{M}$ sodium $m$-periodate, $2 \%$ paraformaldehyde in $\mathrm{PB}$, $\mathrm{pH}$ 7.2. The retinas were dissected and isolated in PBS, and the remaining vitreous humor was gently removed with nitrocellulose filters. The isolated retinas were flattened with radial cuts, and most were incubated for $60 \mathrm{~min}$ in $1 \%$ sodium borohydride in PBS. They were rinsed twice for at least $10 \mathrm{~min}$ each and once for at least 60 min more in PBS after this and all succeeding steps, and unless otherwise noted, PBS was used as the diluent for all reagents. The retinas were incubated with primary antisera against G6-gly diluted 1:1000 to $1: 5000$ in PBS containing $0.3 \%$ sodium azide, $0.1-0.3 \%$ Triton $\mathrm{X}-100$ and $1-3 \%$ normal goat serum for $7-12 \mathrm{~d}$ at $4^{\circ} \mathrm{C}$. The tissue was incubated with biotinylated goat anti-rabbit IgG (Vector) at 1:200 for $2 \mathrm{~d}$ and avidinbiotin-peroxidase complex (Vector) at 1:100 for $1 \mathrm{~d}$. The tissue was reacted with diaminobenzidine (DAB; $0.5 \mathrm{mg} / \mathrm{ml}$ ) and hydrogen peroxide $(0.005 \%)$ for $60 \mathrm{~min}$. The retinas were treated with $0.1 \%$ osmium tetroxide for $1 \mathrm{~min}$, dehydrated, and embedded with epoxy resin. Most specimens were mounted vitreal side up on glass slides and observed with oil immersion optics using either a Zeiss Photomicroscope III or a Zeiss Axiophot. To study vertical sections, selected areas of the wholemounted retinas were reembedded in epoxy resin and $40-60 \mu \mathrm{m}$ sections were made with a steel knife on a sliding microtome. Thick vertical sections from the specimens prepared for electron microscopy were also used for LM analysis in some instances (see below).

Vibratome-sectioned retinas. Five retinas fixed with PAF, 4\% paraformaldehyde in $\mathrm{PB}$, or $4 \%$ paraformaldehyde with $0.05-0.1 \%$ glutaraldehyde in PB were isolated as above and embedded in 3\% agarose (type VII, Sigma) in PBS at $40^{\circ} \mathrm{C}$ after borohydride treatment. Serial, horizontal $100 \mu \mathrm{m}$ sections of the central retina and vertical sections parallcl to the horizontal meridian were prepared on a Vibratome to facilitate the infiltration of the reagents. The labeling procedures were the same as described above except that the sections were not treated with osmium tetroxide, and they were dehydrated and mounted on glass slides with Permount (Fisher).

\section{Immunolabeling protocols for electron microscopy}

For electron microscopic (EM) immunolabeling, a two step fixation was usually employed. The first fixative was $4 \%$ paraformaldehyde with $0.05-0.1 \%$ glutaraldehyde in $\mathrm{PB}, \mathrm{pH} 7.2$, for $45-60$ min at 20 or $37^{\circ} \mathrm{C}$. The second was $4 \%$ paraformaldehyde in $\mathrm{PB}, \mathrm{pH} 10$, overnight at $4^{\circ} \mathrm{C}$. Two retinas were fixed with perfusion of $1.25 \%$ glutaraldehyde, $2.5 \%$ paraformaldehyde in $\mathrm{PB}, \mathrm{pH} 7.0$, for $30 \mathrm{~min}$, and the second fixation step was omitted for one of these. The retinas were isolated and treated with sodium borohydride as above, but they were treated for $10 \mathrm{~min}$ each with an ascending and descending series of ethanol solutions including $10 \%, 25 \%$, and $40 \%$, and the detergent was omitted from the primary antisera (Eldred et al., 1983). The specimens were cut into 1$2 \mathrm{~mm}$ squares by hand or sectioned at $500 \mu \mathrm{m}$ with a Macllwain tissue choppcr prior to incubation in primary antiserum. The remaining steps were the same as described above for the whole-mounts, but the tissue was treated with $1 \%$ osmium tetroxide for $1 \mathrm{hr}$. Six sets of serial, goldsilver sections were made of areas containing labeled bipolar cells. Sections approximately $550 \times 1650 \mu \mathrm{m}$ were used since they covered three openings of 50 mesh grids. They were collected individually on Neoplen W-treated grids without any supporting membrane (Kita, 1984; Kouyama and Hashimoto, 1989). The sections were stained with uranyl acetate ( $2 \%$ in $50 \%$ methanol, $60 \mathrm{~min}$ ) and lead citrate ( $0.2 \%$ aqueous, $2 \mathrm{~min}$ ), observed, and photographed with a JEOL $100 \mathrm{CX}$ electron microscope.

Reconstruction of serial electron micrographs. Several labeled bipolar cell dendrites found in the near-periphery (approximately $5 \mathrm{~mm}$ from the fovea) were three-dimensionally reconstructed around their synaptic contacts with cone pedicles. Electron micrographs were taken at $16,000 \times$ magnification and reconstructed using MONTAGE software for IBM PCAT compatible computers kindly provided by Dr. Robert Smith (University of Pennsylvania).

\section{Quantitative studies of labeled bipolar cells}

Diameters of the perikarya. The diameters of labeled bipolar cells were measured in both a whole-mounted retina and a series of horizontal 

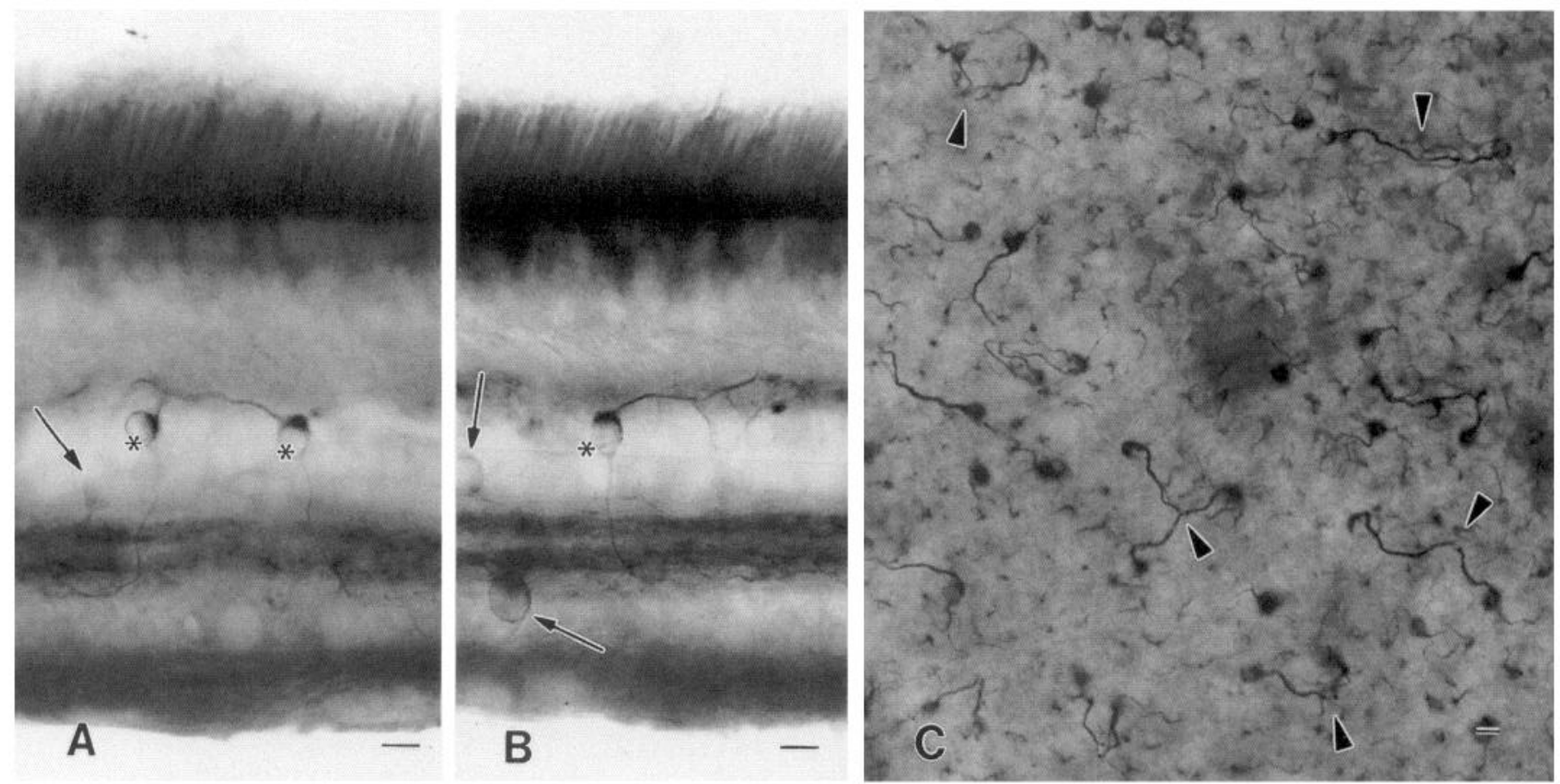

Figure 1. Light micrograph of G6-gly-IR bipolar cells (asterisks) of peripheral retina in vertical sections $(A$ and $B)$ and in a horizontal view of a whole-mount $(C)$. The labeled bipolar cells had one or a few dendrites that ran obliquely through the OPL and an axon that ramified in the innermost stratum of the IPL. Amacrine cells were also labeled (arrows in $A$ and $B$ ), and their dendrites marked second and fourth strata of the IPL. Note that the labeled axons ramified exclusively in the fifth stratum, proximal to the labeled amacrine cell processes. Arrowheads in $C$ indicate the locations of presumptive cone pedicles where the labeled dendrites converged. Scale bars, $10 \mu \mathrm{m}$.

Vibratome sections. Camera lucida drawings of labeled bipolar cell perikarya at their maximum diameters were made using $100 \times$ oil immersion optics on $98 \mu \mathrm{m}^{2}$ areas for every $5^{\circ}$ of eccentricity along the horizontal meridian. Three drawings were made on, as well as approximately $300 \mu \mathrm{m}$ above and below, the horizontal meridian of the retina, which was defined as the line connecting the center of fovea and optic disk and extended to the periphery. The distance between the foveal center and the edge of the optic disk was measured in each retina and taken as $15^{\circ}$ of visual angle (de Monasterio et al., 1985). Every measured distance was converted into degrees of visual angle using that factor without compensation for changes at large eccentricities, and the correction for shrinkage during fixation, dehydration, and embedding was thus done automatically. The drawings were digitized with a Macintosh to calculate diameters of the bipolar cells using IMAGE software.

Locations of labeled bipolar cells in inner nuclear layer. The relative depths of the labeled bipolar cell perikarya in the inner nuclear layer (INL) were measured with Vibratome sections made parallel to the horizontal meridian. Camera lucida drawings representing lengths of $380 \mu \mathrm{m}$ each were made at every $5^{\circ}$ of eccentricity. The depth of the center of nucleus of each of the labeled bipolar cell and the thickness of INL at each point were measured for each cell and expressed as a percentage of the distance from the outer plexiform layer (OPL) to the IPL.

Bipolar cell density. The spatial distribution of labeled bipolar cells was analyzed in three whole-mounted retinas and a reconstructed series of horizontal, Vibratome sections of one central retina. The density of the labeled bipolar cells was measured along the horizontal meridian at every $5^{\circ}$ of visual angle. Three sets of measurements were made at each eccentricity as described above. The labeled perikarya falling within a square of $244 \times 244 \mu \mathrm{m}$ were counted using $40 \times$ oil immersion optics and converted to cells per square degree of visual angle using previously published values (de Monasterio et al., 1985).

\section{Procion black labeling of blue cones}

G6-gly-immunoreactive (G6-gly-IR) bipolar cell contacts with blue cones were examined using a double-labeling technique. Cones were labeled with Procion black using the procedure described by McCrane et al.
(1983). Briefly, $50 \mu \mathrm{l}$ of $15-45 \%$ Procion black H-SPL (PRO Chemical and Dye, Inc.) suspension in sterilized, distilled water was injected intraocularly just behind the lens in three macaques anesthetized with pentobarbital. After 18-22 hr of continuous anesthesia, the monkeys were killed with an overdose of pentobarbital, and the eyes were enucleated. The eyes were fixed with PAF and processed for LM immunohistochemistry in whole-mounts as described above and mounted vitreal side upward. There is a considerable amount of evidence (reviewed by de Monasterio et al., 1981) that blue cones are labeled by this technique, but since the evidence is indirect, the labeled cells should be called "presumptive short-wavelength-sensitive cones." For the sake of clarity, however, they are simply called "blue cones" in this article. This double-labeling procedure made it possible to observe blue cones and G6-gly-IR bipolar cells labeled in the same retina. Although the blue cone labeling was not complete, we could find areas with relatively regular mosaics of labeled blue cones and apparently complete immunolabeling. The light microscopic analyses of neuronal connections between the G6-gly-IR-labeled bipolar cells and Procion black-labeled blue cones were done only in those areas.

\section{Results}

We labeled bipolar cells in every species of macaque tested, and no species differences in the morphology of labeled cells were observed. The results described below are based mainly on retinas from $M$. mulatta. Although all four antisera yielded qualitatively similar results, the best labeling was obtained using antisera 821206 \#37 or R6B16, and those were used most frequently. The morphology of the labeled bipolar cells was the same regardless of the fixation or labeling technique. Generally, the best labeling for light microscopy was obtained using PAF fixation, and the other fixatives yielded fainter or less uniform labeling. For electron microscopy, perfusion with $1.25 \%$ glutaraldehyde, $2 \%$ paraformaldehyde for $30 \mathrm{~min}$ without postfixation gave the best results. 

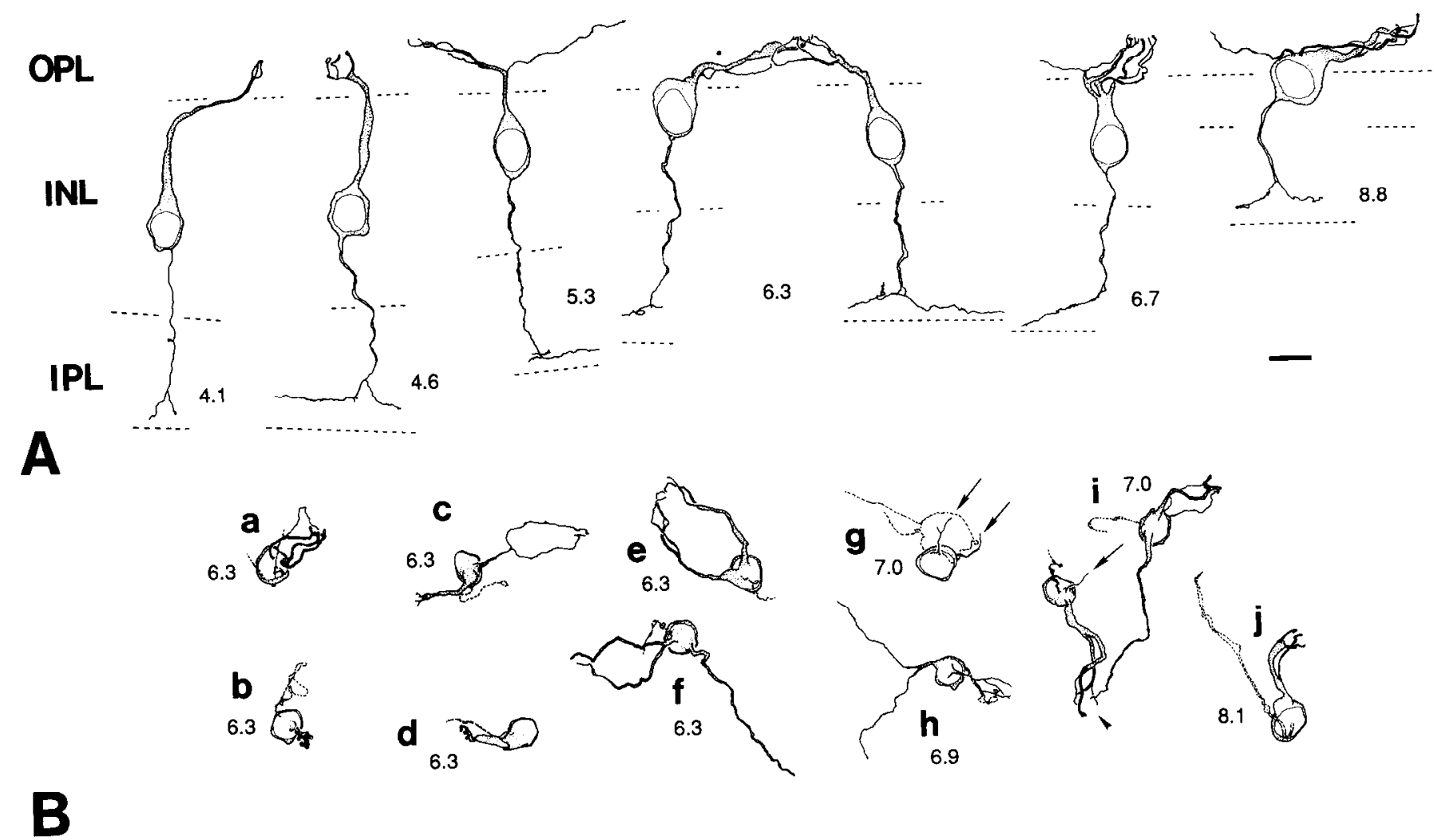

Figure 2. Camera lucida drawings of G6-gly-IR bipolar cells of peripheral retina in vertical $(A)$ and horizontal $(B)$ views. The fovea is located to the left at the distance indicated for each drawing (in $\mathrm{mm}$ ). The broken lines in $A$ indicate the approximate borders of the retinal layers. Axons and their arbors are shown by broken lines in $B$. Most of their dendritic terminals showed bifurcations and terminal specializations suggesting synaptic contacts with cone pedicles. The arrowhead indicatcs a sitc of convergence of dendritcs of two bipolar cclls, wherc a conc pedicle was presumed to be located. Arrows indicate "blind" dendrites that taper and end without any specializations. $O P L$, Outer plexiform layer; INL, inner nuclear layer; $I P L$, inner plexiform layer. Scale bar, $10 \mu \mathrm{m}$.

\section{Morphology of G6-gly-IR-labeled bipolar cells}

G6-gly-IR neurons. Bipolar cells throughout the retina were labeled with antisera against G6-gly, as described previously (Marshak et al., 1990). We observed labeling in vertical sections made from all the specimens processed by the various LM and EM procedures. In the best preparations, the G6-gly-IR bipolar cells looked as though they had been labeled by the Golgi method (Fig. 1). Dendrites in the OPL, somata in the INL, and axons in the IPL were filled with dark brown material characteristic of the peroxidase reaction with $\mathrm{DAB}$, but the nuclei were not labeled. The labeled bipolar cells were easily distinguished from the amacrine cells that were also labeled (Marshak et al., 1990). Their perikarya were smaller and located more distally in the INL. Unlike the amacrine cell dendrites, their thin, but densely labeled, axons ran through the IPL without bifurcation until the fifth stratum.

Whole-mount preparations were made from eight retinas, five from $M$. mulatta and three from $M$. fascicularis. Although the labeling was consistent in the peripheral retina, it was difficult to completely label the central retina. The labeling became faint within $10^{\circ}$ of the fovea or the optic disk. The labeling in the dendrites disappeared first, followed by that of perikarya, and finally, only the axons and their axon terminals were labeled. No labeling was obtained within $5^{\circ}$ of either the fovea or the optic disk in whole-mounts. Apparently, the central retina was too thick to allow infiltration of the reagents since five retinas sectioned with a Vibratome showed good labeling throughout (see Fig. 3).

G6-gly-IR labeled bipolar cells in peripheral retina. Figure 1 shows G6-gly-IR bipolar cells in vertical $(A, B)$ and horizontal views $(C)$. Figure 2 shows camera lucida drawings of representative G6-gly-IR bipolar cells chosen from several locations in the peripheral retina. The distances from the fovea (in $\mathrm{mm}$ ) are indicated. The perikarya were $7-9 \mu \mathrm{m}$ in diameter and located in the first or second row of the INL, and the axons descended vertically through the IPL. The axons were less than $1 \mu \mathrm{m}$ in diameter and did not ramify in either of the two strata containing extensive plexuses of G6-gly-IR amacrine cell dendrites (Fig. $1 A, B)$. The labeled axons branched proximal to them from $75-$ $95 \%$ depth in the IPL, or roughly in the fifth stratum of the IPL (Marshak et al., 1990). The labeled axons had very few, if any, expansions as they descended through the IPL, but there were numerous expansions on the axonal arbors in stratum 5 .

G6-gly-IR bipolar cells usually had a single dendrite that ran vertically through the INL and branched upon reaching the OPL. This part of the dendrite was a direct continuation of the perikaryon, typically having a diameter of at least $2 \mu \mathrm{m}$ (Fig. $2 A$ ). In the peripheral retina, however, the somata of labeled bipolar cells, themselves, sometimes protruded into the OPL (Fig. $2 A$ ). In these instances, two or more dendrites branched directly from the perikarya. After their first bifurcation in the OPL, the dendrites rarely branched, and their diameters ranged from $0.2 \mu \mathrm{m}$ to $2 \mu \mathrm{m}$. Most dendrites of labeled bipolar cells 

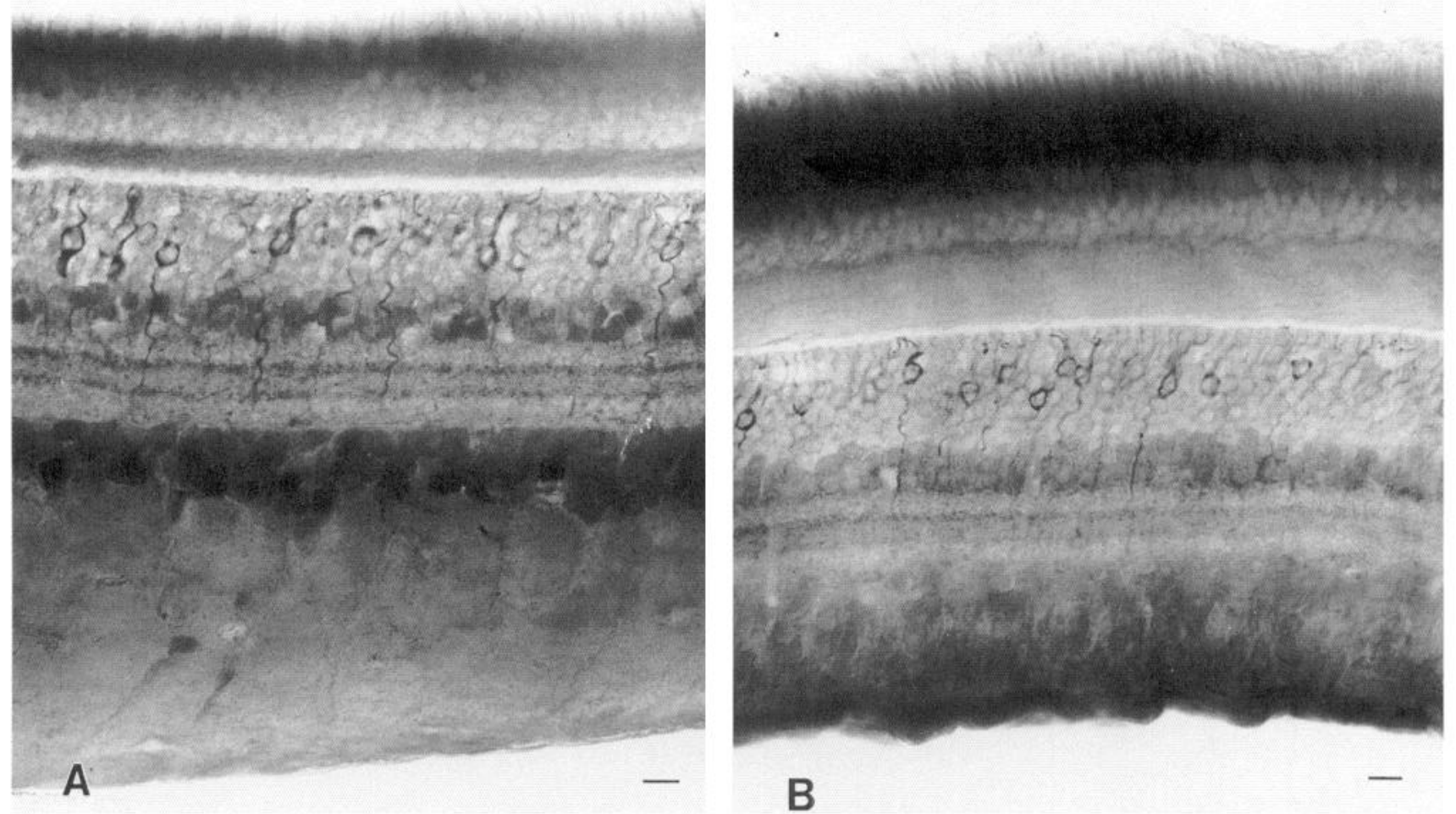

Figure 3. Light micrographs of G6-gly-IR bipolar cells in vertical Vibratome sections in the central retina, near the optic disk $(A)$ and near the fovea $(B)$. The labeled bipolar cells had smaller perikarya and longer processes and were more numerous than in the periphery. In both micrographs, the fovea is at the right and optic disk is at the left. Scale bars, $10 \mu \mathrm{m}$.

did not contact cone pedicles located just above them (Figs. 1, 2). Instead, they ran obliquely through the OPL and contacted a subpopulation of cone pedicles located $10-50 \mu \mathrm{m}$ from the perikarya, passing the cone pedicles in between without forming branches or any other specializations. When the labeled dendrites reached the cone pedicles they contacted, they tapered to less than $1 \mu \mathrm{m}$ in diameter and often divided further. These final branches varied from $0.1 \mu \mathrm{m}$ to $1 \mu \mathrm{m}$ in diameter, and they were invaginated deeply into the pedicles. Sometimes, there were also a few fine dendrites that simply tapered and ended without reaching any pedicles like the "blind dendrites" described by Mariani (1984b).

Camera lucida drawings of labeled bipolar cells in horizontal view of peripheral retina are shown in Figure $2 B$. Each bipolar cell had one to four major dendrites whose diameters varied from 0.2 to $2 \mu \mathrm{m}$. The lengths of the dendrites ranged from 10 to $50 \mu \mathrm{m}$, and in the peripheral retina, no preference was noticed, either in the orientations of the labeled dendritic arbors or in the positions of the cones they contacted relative to the fovea (Fig. $2 B$ ). The axonal arbors are also shown in Figure $2 B$ with a broken line. As observed in vertical sections, the axons had one to three branches that ranged from $5 \mu \mathrm{m}$ to $35 \mu \mathrm{m}$ in length and were typically shorter than the dendrites.

Bifurcations were infrequent in the midportions of the dendrites, and even when they divided on the way, both dendrites typically contacted the same pedicle (Fig. $2 B, c, e, f$ ). At the ends of each process, small spines or expansions were commonly seen. Some processes showed only indistinct ovoid or spherical expansions at their terminals whose detailed structure could not be resolved; these were likely to be sprays of fine processes. In others, there was no expansion, but the terminal appeared to meander, suggesting that very fine spines were present (Fig. $2 B$, $e, f, h$ ). Some bipolar cells had only a single dendrite (Fig. $2 B$, $b, d, j)$ and contacted a single cone pedicle where they formed a terminal specialization similar in some respects to the "bouquet" of midget bipolar cells (Polyak, 1941; Boycott and Dowling, 1969). The dendritic terminals were considerably less dense than those of midget bipolar cells, however. Some bipolar cells had two or more major dendrites but contacted a single cone pedicle (Fig. $2 B, a, e$ ).

As shown in Figure $2 B, i$, several labeled dendrites originating from two or more bipolar cells often converged upon points that must have been the sites of cone pedicles, but it was difficult to observe the cone pedicles themselves in the whole-mounted specimens (Fig. $1 C$, arrowheads). The terminal specializations of the dendrites of bipolar cells like $f$ and $h$ in Figure $2 B$ were less conspicuous, but these dendrites almost certainly contacted presumptive cone pedicles since there were other labeled dendrites (not shown) converging at the sites where they terminated. These bipolar cells had dendritic connections with one (Fig. $2 B$, $a, b, d, e, i$ left, $j$ ), two (Fig. $2 B, c, f, i$ right), or three (Fig. $2 B, h$ ) cone pedicles.

There were, however, some dendrites without such specialized endings, although other dendrites of those bipolar cells had them in some instances. As shown in Figure $2 B$ ( $i$, arrow), these dendrites simply tapered and ended without any specialization, and no dendrites from other labeled bipolar cells were seen there. These dendrites correspond to "blind dendrites" that ended in the middle of OPL in vertical sections (Mariani, 1984b). A few labeled bipolar cells had such dendrites exclusively (Fig. $2 B, g$ ). 

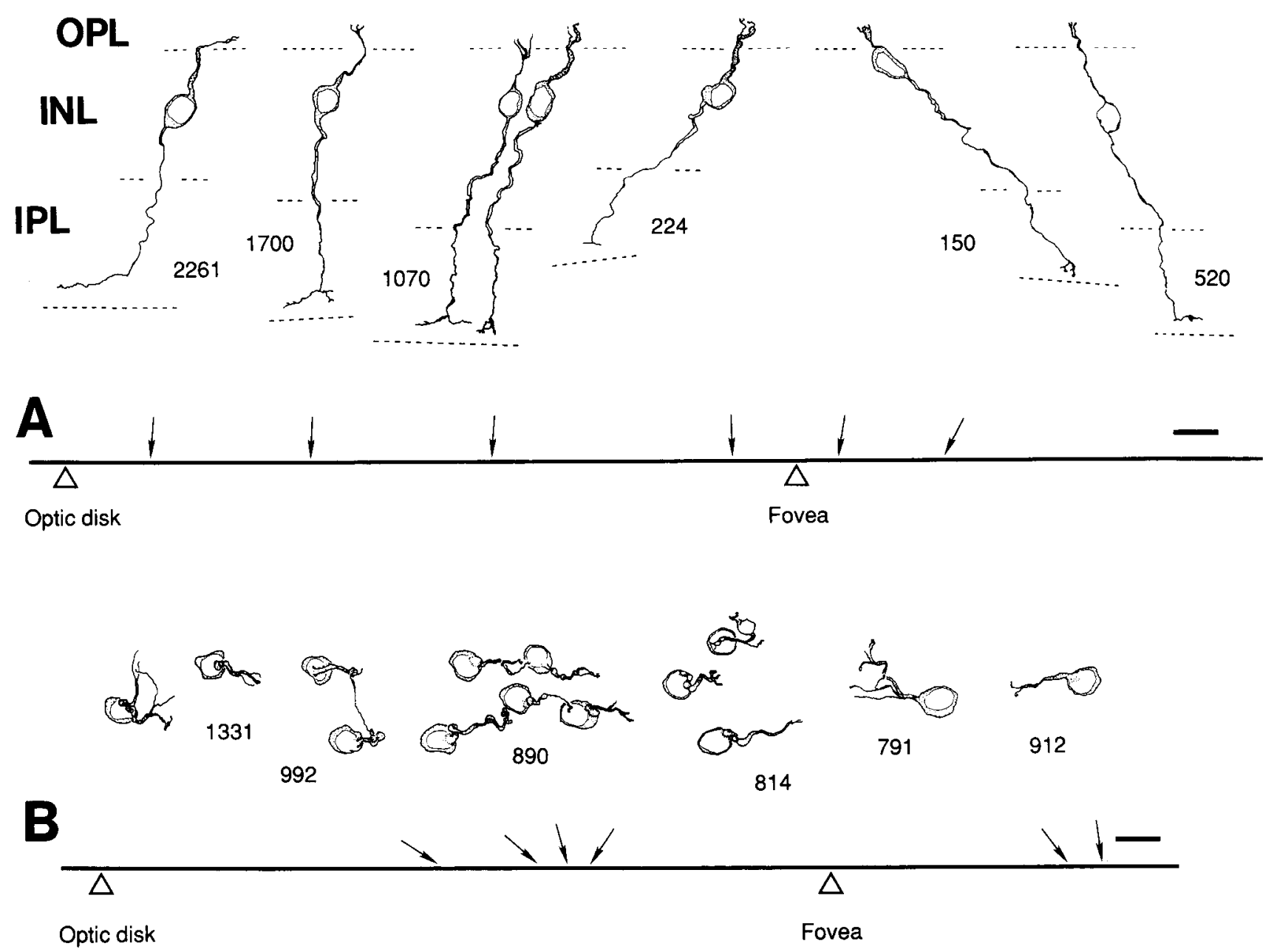

Figure 4. Camera lucida drawings of G6-gly-IR bipolar cells of central retina in vertical $(A)$ and horizontal $(B)$ views. Cells near the horizontal meridian were drawn; distance from the fovea and the location on the horizontal meridian are indicated for each drawing (in $\mathrm{m}$ ). The dendritic terminals of labeled bipolar cells had specializations suggesting synaptic contacts with cone pedicles. Note the orientation of dendrites toward the fovea and axons away from the fovea. The broken lines indicate approximate borders of the retinal layers. OPL, Outer plexiform layer; INL, inner nuclear layer; $I P L$, inner plexiform layer. Scale bars, $10 \mu \mathrm{m}$.

G6-gly-IR bipolar cells in central retina. Bipolar cells in central retina were studied using Vibratome-sectioned preparations because it was impossible to obtain good labeling of the central area in whole-mounts. Figure 3 shows micrographs of G6-glyIR bipolar cells in vertical Vibratome sections taken from the area between the fovea and the optic disk. Distinct subpopulations of bipolar cells and amacrine cells were labeled, as in peripheral retina. In the fovea centralis, there were several G6gly-IR neurons (not shown), but it was not possible to determine whether they were bipolar cells or amacrine cells.

G6-gly-IR bipolar cells could first be identified on the foveal slope. The labeled bipolar cells had smaller perikarya and a higher density in the center than in the periphery (Fig. 3). Figure $4 A$ shows camera lucida drawings of bipolar cells in vertical sections accompanied by a diagram indicating their locations. The labeled bipolar cell perikarya were found mainly in the outer half of the INL, which had five or more layers of perikarya in this region (Figs. 3, 4). The axons were also longer than in the periphery, reflecting the increased thickness of INL and IPL. They reached stratum 5 of the IPL, which again could be identified by the labeled amacrine cell processes above it. In stratum 5 , the axons had arbors with expansions similar except in size to those in the periphery (Figs. 3, 4A). The central G6-gly-IR bipolar cells had a single main dendrite that ran through the INL. This part of the dendrite was also longer than in the periphery, as the INL was thicker. The dendrites had almost no arborizations in the OPL, and in most cases, they ended at a single cone pedicle with several terminal bifurcations and swellings (Fig. 4A).

Camera lucida drawings of horizontal Vibratome sections are shown Figure $4 B$. They were taken from several locations along the horizontal meridian, as indicated in the lower diagram. The dendrites had few arborizations, most having only one main stem. This part of the dendrite usually ran toward the fovea (Figs. 3, 4). When they reached the OPL, they usually contacted a single cone pedicle without further bifurcation. There were some bipolar cells, however, that apparently contacted two cones (indicated as 992 in Fig. 4B). The secondary branches that traversed the OPL after the first bifurcation were shorter than in the periphery, as expected from the shorter distances between blue cones. The labeled axons descended in a wavy course through the INL, reflecting the dense packing of bipolar cell somata in the central retina (Figs. 3, 4A). The axons ran obliquely away from the fovea in the INL, but they descended perpendicular 


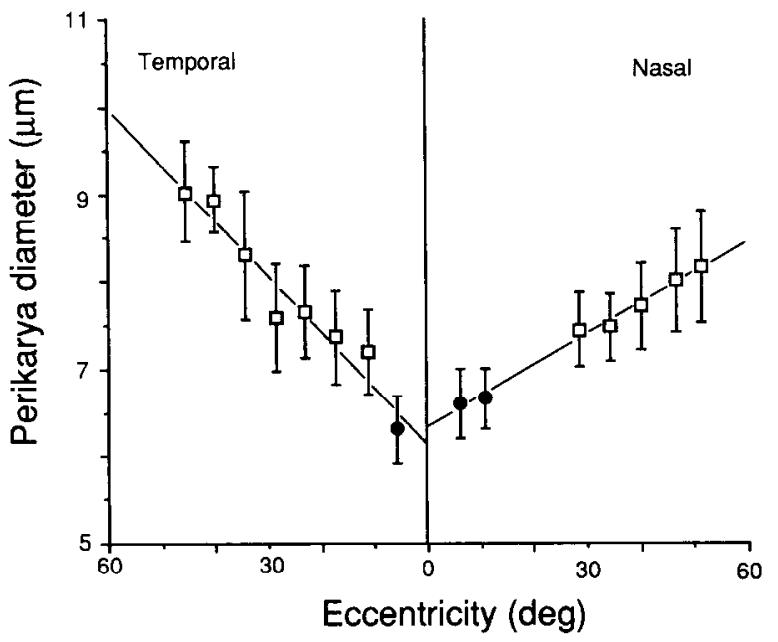

Figure 5. Diameters of G6-gly-IR bipolar cell perikarya as a function of eccentricity along the horizontal meridian. The diameter was defined as the diameter of a circle having the same area as a drawing at the widest parts of labeled bipolar cell perikarya in a whole-mounted retina (open rectangles) or in a horizontal Vibratome section (solid circles). The diameters were smallest in the central retina and largest in the temporal periphery, but the transition was smooth.

to the retinal plane in the IPL (Fig. 4A, 1070-520). Thus, the labeled central bipolar cells had dendrites oriented toward the fovea and axons toward the periphery.

Quantitative studies of G6-gly-IR bipolar cells. To determine whether these differences between labeled bipolar cells in central retina and peripheral resulted from regional variation within a single type, three features of labeled bipolar cell perikarya were studied as a function of eccentricity along the horizontal meridian; the diameters, the depth in the INL, and the density.

Diameters of perikarya. Figure 5 shows the distribution of perikaryal diameters along the horizontal meridian measured from one whole-mount and one central retina sectioned in the horizontal plane with a Vibratome. The diameter was defined as that of a circle having the same area as the labeled bipolar perikaryon at its widest point. The diameters of the perikarya were smallest near the fovea; the mean and SD were $6.3 \pm 0.4$ $\mu \mathrm{m}$. The diameter increased gradually with eccentricity and excceded $9 \mu \mathrm{m}(9.0 \pm 0.6 \mu \mathrm{m})$ at temporal periphery. There was no indication of segregation into two or more distinct types, but the slope of the function was obviously steeper in the temporal hemiretina than in the nasal hemiretina. A line fitted for the temporal half was $Y=0.064 X+6.15\left(R^{2}=0.938\right)$ and for the nasal half was $Y=0.035 X+6.34\left(R^{2}=0.989\right)$, where $Y=$ diameter and $X=$ eccentricity in degrees.

Depth of perikurya. The perikarya of labeled bipolar cells were usually located in the first or second rows of the INL in the mid periphery. They seemed to be buried deeper in the INL in the central retina and closer to the OPL in the far periphery, however. The depths of labeled bipolar cell nuclei were measured from vertical Vibratome sections made parallel to the horizontal meridian. The distribution of relative depths of labeled perikarya in the INL is shown in Figure 6 . They were consistently found at $20-40 \%$ of the distance from OPL to IPL $(33 \pm 11 \%$, mean $\pm \mathrm{SD}$ ), notwithstanding their location. The relative depth was in this range even in the far periphery because the depth was measured at the center of their nuclei, and there were only two or three perikarya in the INL there. Likewise, the impression

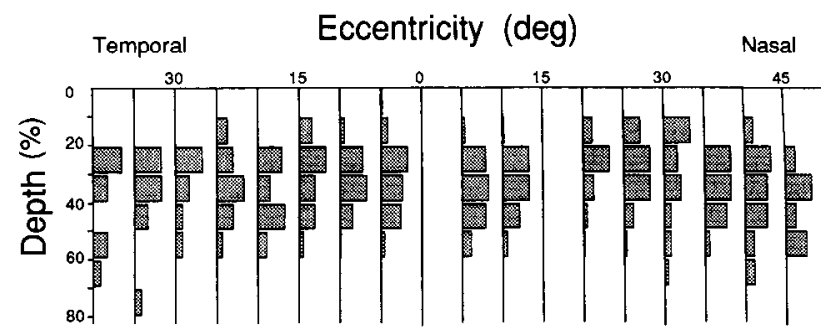

Figure 6. Histograms of the depths of the centers of G6-gly-IR bipolar cell nuclei in the INL at several eccentricities along the horizontal meridian. The data were grouped in bins of $10 \%$, and each histogram was normalized to its peak value. Most bipolar cells were located between $20 \%$ and $40 \%$ of the distance from the OPL to the IPL, and there was no apparent change with eccentricity.

that the labeled perikarya were deeper in central retina was due to the greater thickness of the INL there. There was no significant difference between the distributions by a simple ANOVA, 5\% confidence level.

Density distribution. Figure 7 shows the density of labeled bipolar cells as a function of eccentricity along the horizontal meridian. These were obtained from three whole-mounts for peripheral retina and one series of horizontal, Vibratome sections for central retina. The density was highest in central retina where it exceeded 140 bipolar cells per square degree, and it gradually decreased with eccentricity, becoming less than 10 bipolar cells per square degree at the most temporal periphery. There was no indication of major differences between individuals, but the density in the nasal half was consistently higher than in the temporal half.

\section{Synaptic connections between bipolar cells and blue cones}

In order to identify the cones providing input to the G6-GlyIR bipolar cells, blue cones were selectively labeled with Procion

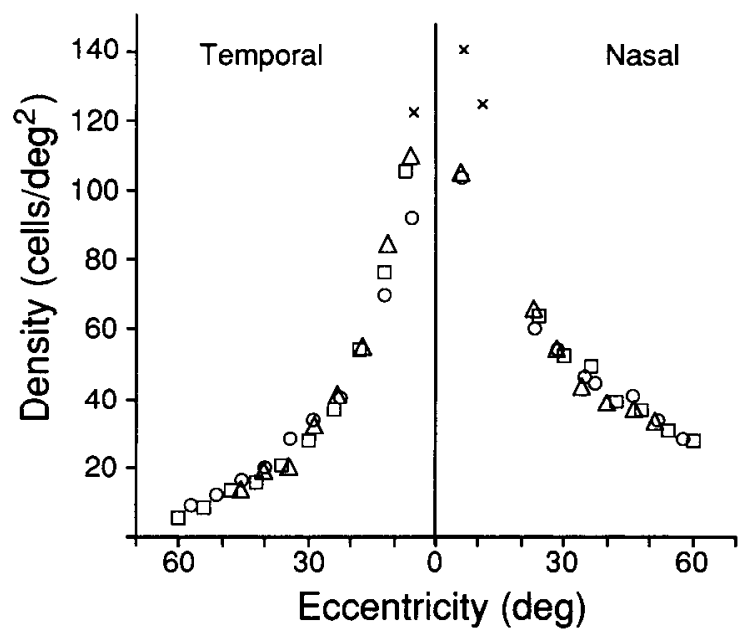

Figure 7. Density of G6-gly-IR bipolar cells as a function of eccentricity along the horizontal meridian. Data from four retinas of three monkeys were included; each symbol represents a mean of three measurements for each eccentricity for each retina. Retinas indicated with open squares and open triangles were taken from the same monkey. The measurements indicated with $\times$ were taken from a series of horizontal Vibratome sections through the central retina, and the others were taken from whole-mounts. There was a greater than 10 -fold difference between the highest density in the center and the lowest density in the temporal periphery. 

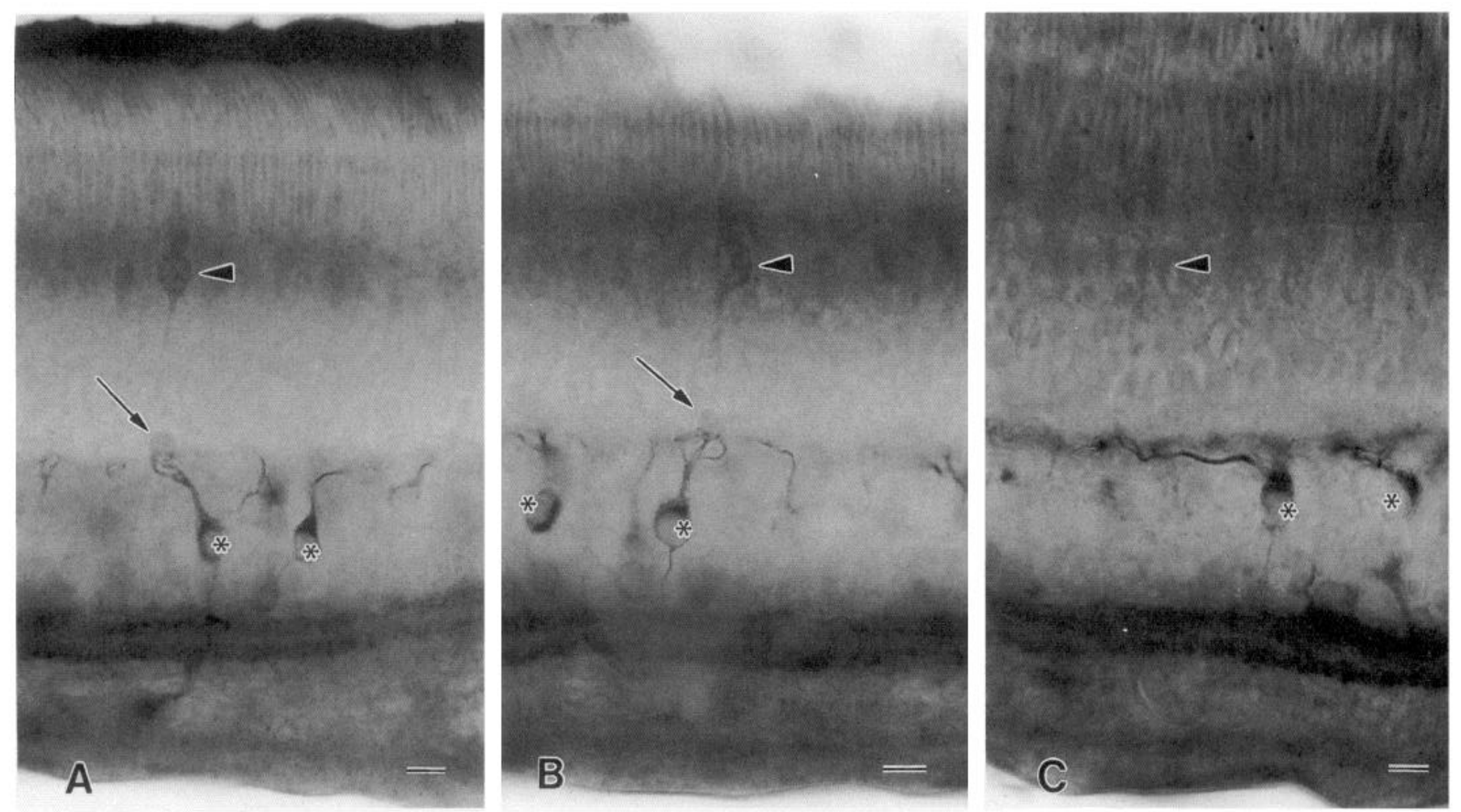

Figure 8. Vertical sections of a retina double-labeled with Procion black for blue cones (arrowheads) and anti-G6-gly (asterisks). Note that the blue cones were labeled with Procion black from their outer segments to their pedicles. The dendrites of labeled bipolar cells reached and invaginated into the pedicles of labeled blue cones (arrows). Scale bars, $10 \mu \mathrm{m}$.

black SPL (McCrane et al., 1983), and their connections with labeled bipolar cells were studied. In total, three retinas from three monkeys (two M. mulatta and one $M$. fascicularis) were double labeled for blue cones and bipolar cells. We studied the connections between the cones and bipolar cells in the ventral quadrant of one retina (M. mulatta; at least 18 years old) where labeling was optimal with both methods. The other retinas showing incomplete labeling or fixation artifacts were only analyzed qualitatively, but they yielded similar results.

Dendritic contacts between bipolar cells and blue cones. Figure 8 shows representative vertical sections made from a wholemount of double-labeled retina. The blue cones were labeled with Procion black in their entirety (arrowheads and arrows in Fig. 8). The dendrites of labeled bipolar cells (asterisks in Fig. 8) contacted the pedicles of the labeled blue cones, and although there were sometimes bifurcations, all of them seemed to converge onto the dye-labeled pedicles (arrows in Fig. 8). Figure 8, $B$ and $C$, also shows other dendrites originating from a labeled bipolar cell whose perikaryon is out of the plane of focus converging onto the same pedicle. Terminal specializations were found at the invaginating dendritic tips (Fig. 8), as described above.

Representative micrographs of bipolar cells and blue cones in horizontal view are shown in Figure 9. Both micrographs were taken from exactly the same area but with different focal planes. The mosaic of blue cone inner segments labeled with the dye is shown in Figure 9A, and that of peroxidase-labeled bipolar cell perikarya and primary dendrites is shown in Figure $9 B$. The locations of Procion black-labeled blue cones observed in Figure $9 A$ are also indicated with arrowheads in Figure $9 B$.
Because these micrographs were taken from peripheral retina, the pedicles of the cones were just beneath the inner segments. Every labeled pedicle received labeled bipolar cell dendritic contacts, and some pedicles were contacted by dendrites converging from as many as three bipolar cells. The labeled bipolar cells and blue cones located in a $244 \times 244 \mu \mathrm{m}$ frame were counted in 10 different areas where both mosaics seemed to be complete. The ratio of labeled bipolar cells to blue cones was $1.4 \pm 0.2$ (mean $\pm \mathrm{SD}$ ) in the ventral retina.

Mosaics of blue cones and bipolar cells. Figure 10 shows a diagrammatic representation of the locations of Procion blacklabeled blue cones and the major dendritic arborizations of the labeled bipolar cells in a representative $500 \mu \mathrm{m} \times 900 \mu \mathrm{m}$ area. All 161 blue cones indicated in this diagram were presynaptic to labeled bipolar cells. The dendrites of most labeled bipolar cells $(83 \%)$ shown in this diagram could be traced to blue cone pedicles, and the rest will be discussed in greater detail below. To rule out the possibility that there were finer dendrites that could not be traced at the magnification needed to cover such a large area, the connections between the labeled bipolar cells and blue cones were analyzed in greater detail in three smaller areas. All labeled bipolar cells and blue cones present in $244 \times$ $244 \mu \mathrm{m}^{2}$ grids were registered, and all dendritic branches of bipolar cells were traced to their destinations using higher magnification. The results of a representative analysis of this type are shown diagrammatically in Figure 11. The connections between the labeled bipolar cells and blue cones were also found to be selective in this detailed analysis, which included 114 bipolar cells.

There was not a strict one-to-one relationship between the 

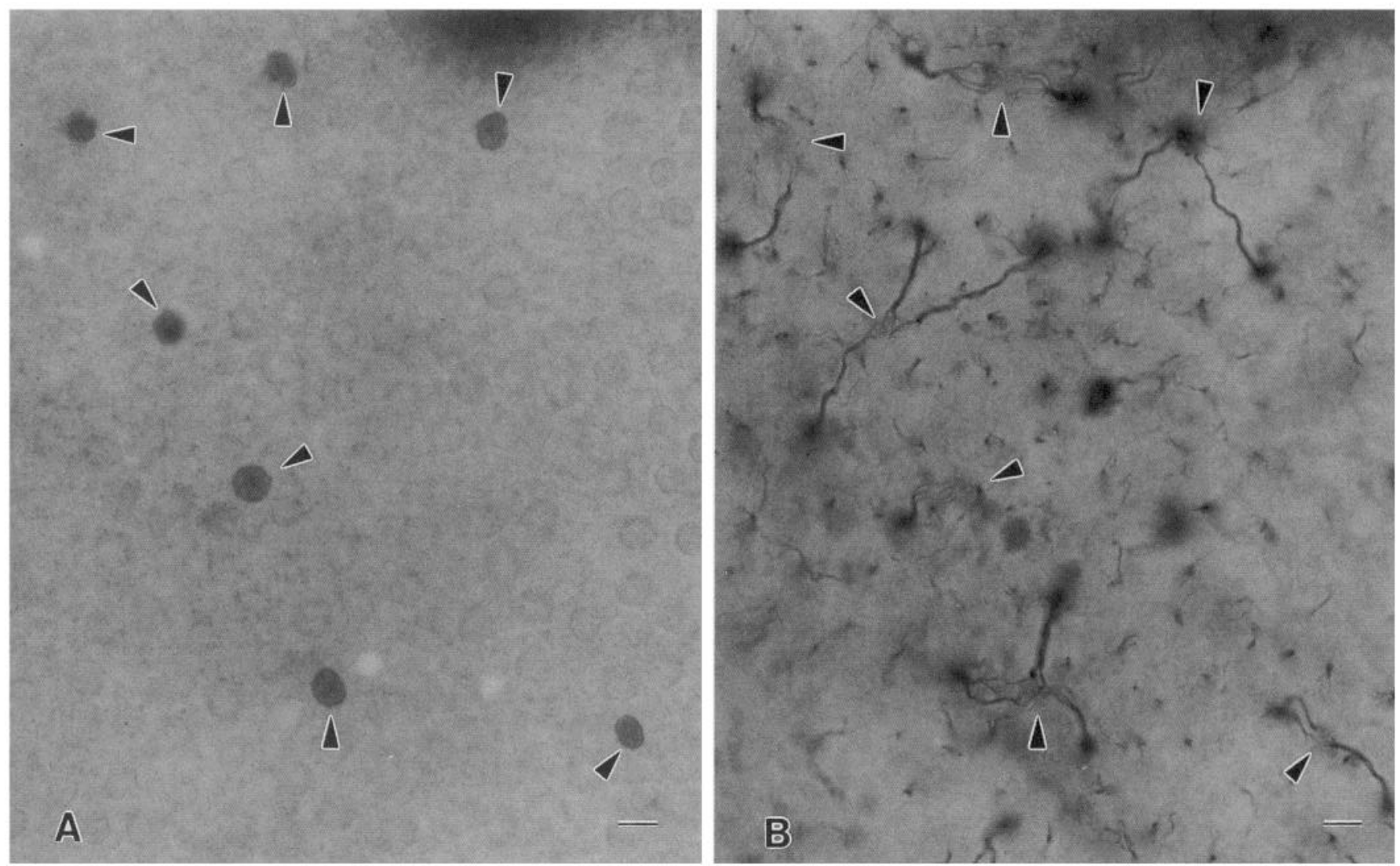

Figure 9. Micrographs of a whole retina double labeled with Procion black for blue cones $(A)$ and anti-G6-gly for bipolar cells $(B)$. These were taken from the same area but at different planes of focus. The locations of blue cone inner segments are indicated by arrowheads in both. The dendrites of labeled bipolar cells contacted blue cones exclusively. Scale bars, $10 \mu \mathrm{m}$.

blue cones and labeled bipolar cells, however. Bipolar cells were postsynaptic to as many as three blue cones, while blue cones were presynaptic to as many as four bipolar cells. The average divergence at the blue cone to the bipolar cell synapse, that is, the number of labeled bipolar cells postsynaptic to each blue cone, shown in Figure 12, was $1.84 \pm 0.7$ bipolar cells. More than half the blue cones were presynaptic to two labeled bipolar cells and approximately one-third to only one bipolar cell. There were also a few cones presynaptic to three or even four bipolar cells.

The convergence at the blue cone to bipolar cell synapse, that is, the number of blue cones presynaptic to each labeled bipolar cell, is also shown in Figure 12. Almost two-thirds of the bipolar cells received input from only one cone. There were also a considerable number of bipolar cells, about one-fourth, receiving input from two cones. On average, a bipolar cell received inputs from $1.22 \pm 0.56$ blue cones. The ratio between the divergence to convergence was close to the ratio of labeled bipolar cells to blue cones, as expected.

As indicated in Figures 11 and 12, about $5 \%$ of the labeled bipolar cells did not contact any blue cones. Several lines of evidence indicate that this resulted from degeneration of blue cones and not from contacts with other cone types. These bipolar cells always had fewer than average dendrites that tapered and ended before reaching any blue cone pedicles, and no specialized structures were found at their terminals. Other labeled bipolar cells had both dendrites that lacked specialized contacts as well as dendrites that made specialized contacts with blue cones.
These bipolar cells were similar to those shown in Figure $2 B$ ( $g$ and $i$ left). Unlike normal dendrites, these tapering dendrites did not end in the vicinity of other labeled dendritic terminals. Conversely, when two or more labeled dendrites converged on a site, a blue cone was always present.

The results described above were obtained from areas with relatively regular mosaics of blue cones. The mosaics of Procion black-labeled blue cones were not always regular, however, as shown in Figure 10. In some regions, blue cones appeared to be missing. Such regions are most clearly shown in Figure 13, where each cone is surrounded by a shaded circle whose diameter is the local mean distance between blue cones. It seems quite likely that some blue cones in the otherwise regular arrangement are missing in the regions left uncovered. A similar analysis done on the mosaic of G6-gly-IR bipolar cells, including those with "blind dendrites," did not show any such deficiency. Figure 13 shows that most of the bipolar cells that had no blue cone contacts were located in the areas that lacked blue cones. Furthermore, convergence of two or more labeled bipolar cell dendrites suggesting synaptic connections onto cones was never observed in the areas without blue cones. This finding suggests that blue cones were missing rather than unlabeled since, if there had been unlabeled blue cones, there would have been converging dendrites from labeled bipolar cells. It looks as though blue cone bipolar cells retract their dendrites after the blue cones they contact have degenerated, but the perikarya survive and maintain a regular mosaic despite the lack of input from cones. Thus, we conclude that the labeled bipolar cells contacted blue 


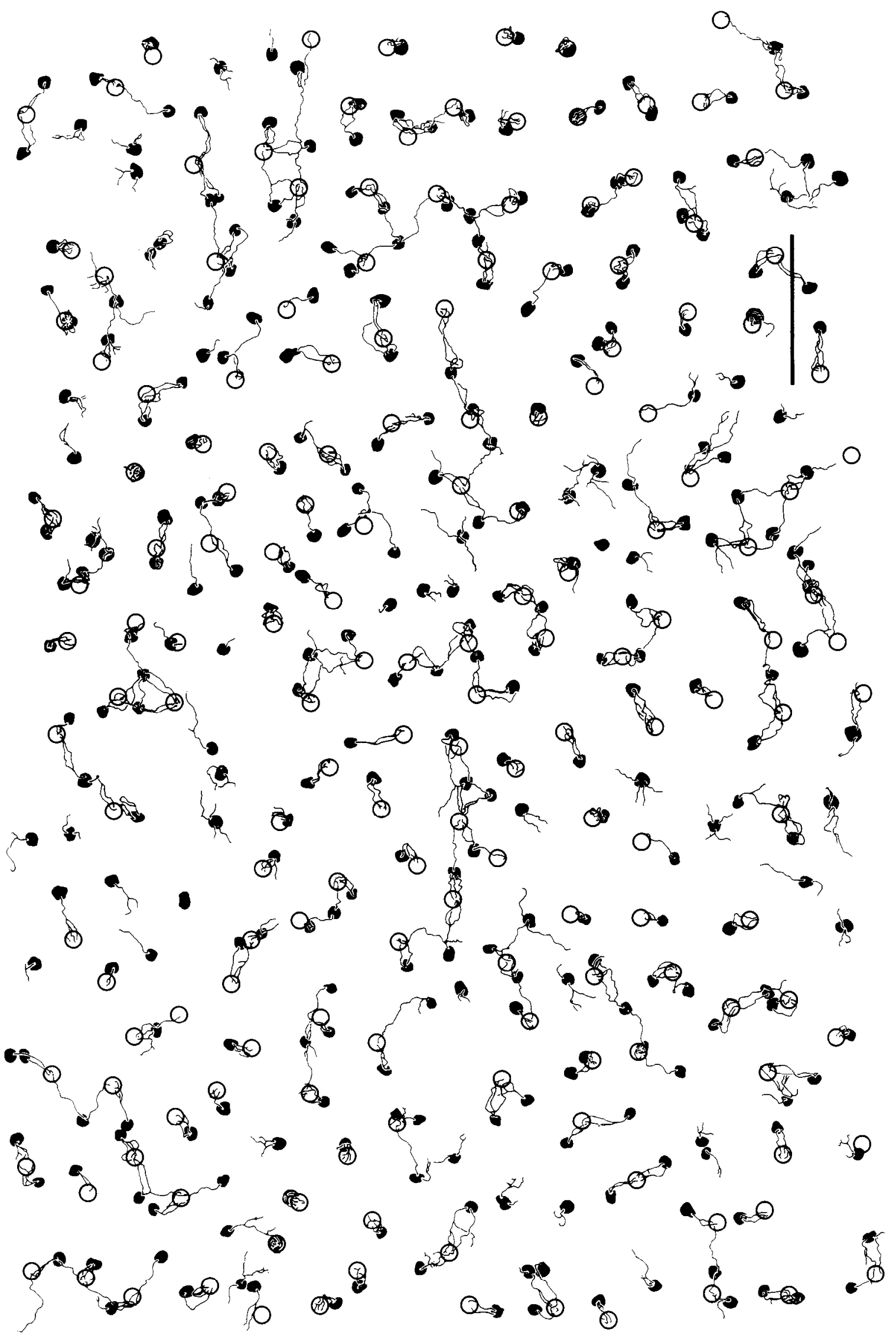

Figure 10. Camera lucida drawing of the major dendritic arborizations of the G6-gly-IR bipolar cells and the mosaic of Procion black-labeled blue cones (open circles) in ventral peripheral retina. Nearly all the bipolar cell dendrites terminated beneath the blue cones, and all blue cones were contacted by bipolar cell dendrites. Scale bar, $100 \mu \mathrm{m}$. 


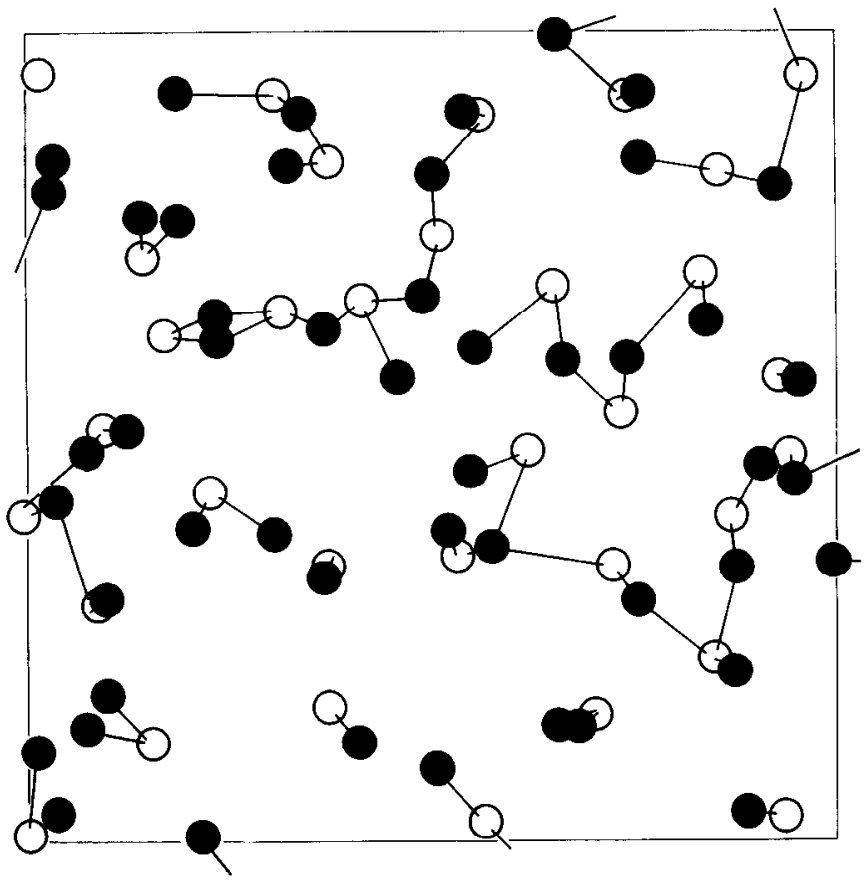

Figure 11. A schematic diagram of the connections between the Procion black-labeled blue cones (open circles) and G6-gly-IR bipolar cells (solid circles) found in a $244 \times 244 \mu \mathrm{m}^{2}$ area in the ventral, peripheral retina. Dendritic connections between blue cones and bipolar cells are represented with a single line regardless the number or the diameter of the dendrites. The labeled bipolar cells received input from blue cones exclusively, but the connection was not one to one. There were bipolar cells that had connections with no cones or as many as three blue cones.

cones exclusively and that the bipolar cells without blue cone contacts seen in this study result from degeneration of blue cones.

\section{Synapses of G6-gly-IR dendrites}

Retinas from six $M$. nemestrina, four $M$. mulatta, and one $M$. fascicularis were processed for electron microscopy, and labeled bipolar cells were observed in all of these. Unfortunately, it was difficult to obtain both good labeling and good tissue preservation at the same time. When the ultrastructure was acceptable, the probability of immunolabeling was greatly reduced. Most observations described below were made on a specimen from peripheral retina of one $M$. mulatta fixed by perfusion with $1.25 \%$ glutaraldehyde and $2 \%$ paraformaldehyde without postfixation, in which both immunolabeling and tissue preservation were adequate. Even in this preparation, it is clear by comparison with our LM results that only a fraction of the population of G6-gly-IR bipolar cells was labeled. Fortunately, those cells that were labeled appeared to be filled almost completely with reaction product. We observed 29 synaptic ribbons related to 10 reconstructed labeled dendrites in eight cone pedicles. One of these pedicles containing two labeled dendrites was completely reconstructed. In addition, several other dendritic terminals were observed but not reconstructed.

Fine structure of labeled bipolar cell dendrites. The labeled bipolar cells were clearly identifiable by the electron-opaque peroxidase reaction product that fillcd cytoplasm but not the nuclei or mitochondria (Fig. 14A). The dendritic arbors were also filled with HRP reaction product and could be traced to a subpopulation of cone pedicles (Fig. 14A,B). Their finest tips, which formed postsynaptic elements, were not always labeled, however. The diameters of labeled processes in the OPL showed a large variation from 0.2 to $2 \mu \mathrm{m}$, corresponding well with the diameters of the dendrites observed by light microscopy.

Most dendritic processes approached the cone pedicle obliquely, as we observed by light microscopy (Fig. 14B). Approximately $2 \mu \mathrm{m}$ from the pedicle, they usually bifurcated several times, forming the terminal specializations that we observed by light microscopy. Most labeled dendritic process had several terminal processes $0.2-1 \mu \mathrm{m}$ in diameter that invaginated into the cone pedicles, ending at the synaptic ribbon. Only the largestdiameter terminals were labeled all the way to the end (Fig. $15 B)$. The finest processes $(0.2-0.4 \mu \mathrm{m}$ in diamcter) werc often unlabeled (see Figs. $15 \mathrm{~A}, 17 \mathrm{C}$ ), and it was necessary to reconstruct the processes. We could not trace every process branching from each labeled bipolar cell dendrite to a ribbon synapse, but

\section{Divergence}

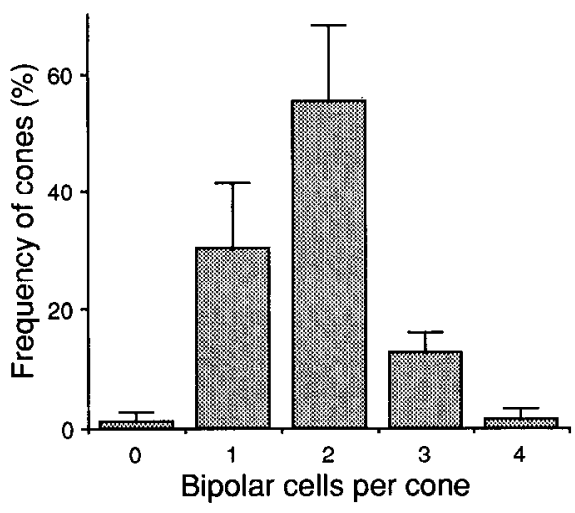

Convergence

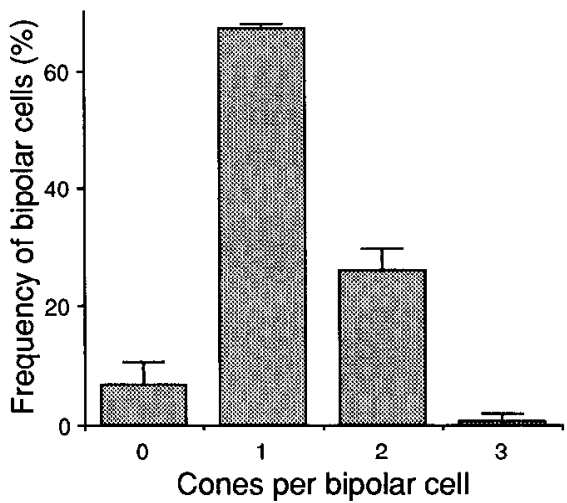

Figure 12. Histograms showing the divergence and the convergence of synaptic connections from blue cones to labeled bipolar cells of the ventral peripheral retina. Each blue cone was presynaptic to as many as four bipolar cells. The numbers of blue cones presynaptic to bipolar cells, defined as the divergence and expressed as a percentage, is shown at the left. More than half the blue cones were presynaptic to two bipolar cells, and onethird were presynaptic to one bipolar cell. On the other hand, each bipolar cell contacted up to three blue cones. The number of bipolar cells postsynaptic to blue cones, defined as the convergence and expressed as a percentage, is shown at the right. Approximately two-thirds of the bipolar cells were postsynaptic to one blue cone, and one-third were postsynaptic to two blue cones. The bipolar cells without blue cone inputs are described in greater detail in the text and in Figure 13. 


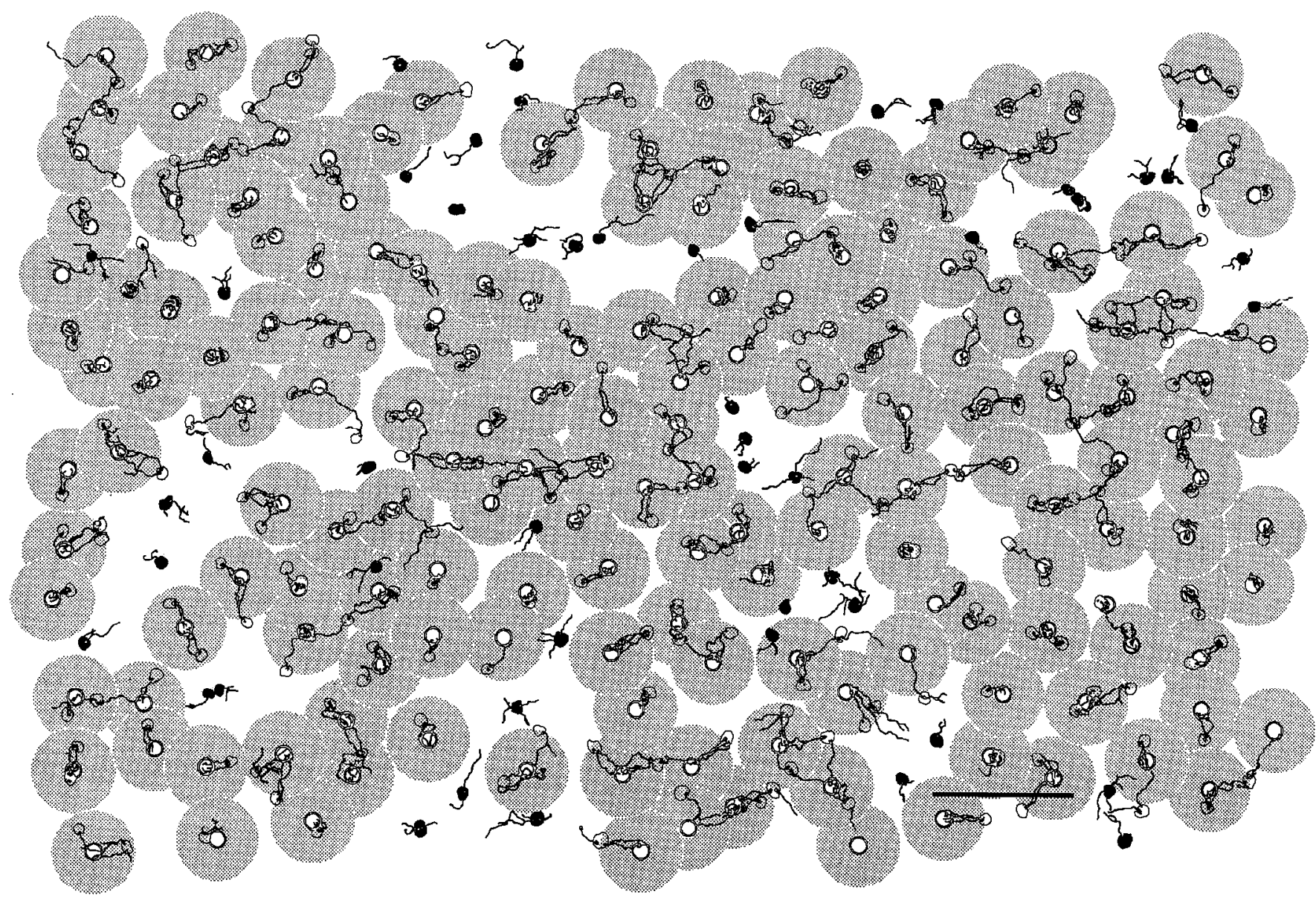

Figure 13. Blue cones (open circles) from Figure 10 surrounded by a circle having a diameter of the local average distance between blue cones distance (shaded circles) are shown. There were several areas in which blue cones were apparently missing. The bipolar cells that had no contacts with blue cones (solid) were most common in these areas.

at least one such process from each labeled dendrite within $1-$ $2 \mu \mathrm{m}$ of the pedicle was found to reach a ribbon synaptic complex.

Ribbon synapses. Where possible to follow, labeled processes invaginated into pits surrounded by cone plasma membrane and two lateral elements and terminated as central elements of ribbon synapses $(n=29)$. They were separated from the ribbon by a distance of about $0.1 \mu \mathrm{m}$ in most cases since junctions between the lateral elements usually shielded them from the synaptic ridge (see Figs. 15A, 17). Figure $15 B$ shows an example of a less common type of ribbon synapse where the central element was directly juxtaposed to the cone pedicle membrane at the synaptic ridge. In this instance, however, junctions between lateral elements shielded that central element from the synaptic ridge in the adjacent sections (not shown). Other features could be seen such as cytoplasmic membrane densities and accompanying opaque materials in the cleft between the sides of the labeled processes and the surrounding pedicle membrane (see Figs. 15A, 17B,C). Such features characterize narrowcleft junctions (Lasansky, 1972; Mariani, 1984a) and the typical ribbon synapses previously described in macaque cone pedicles (Dowling and Boycott, 1966; Raviola and Gilula, 1975).

In addition to these typical ribbon synapses, we observed two other types of ribbon synaptic complexes. One, shown in Figure $15 B$ and illustrated in Figure $16 B$, had a central element of large diameter $(0.7 \mu \mathrm{m}$; Fig. $15 B)$ that was related to two or more ribbon synaptic complexes simultaneously. It was the central element of three ribbon synapses surrounding it, but each ribbon had its own complement of lateral elements (Fig. 16B). The ribbon synaptic complexes shared one indentation containing a single, large central element, and as a result, the lateral elements appeared compressed (Fig. 15B). In eight cone pedicles, we observed four complexes of this type, three containing three ribbons and one containing two ribbons.

In another variation, each ribbon synapse had as many as three bipolar cell dendrites as central elements. Figure 17 shows representative electron micrographs of this type of contact from a scrics of scctions, and Figure $16 \mathrm{~A}$ shows a threc-dimensional reconstruction of this ribbon synapse. A ribbon was observed in 11 consecutive sections with lateral elements on both sides. While these two lateral elements could be traced along the entire extent of the ribbon, three processes were observed to take the position of central element in turn (Fig. 17A-F). One of the central elements was labeled (Fig. 17C,D), but although there were no apparent ultrastructural differences between the three central elements, the identity of the other types is uncertain. In a single section, this synapse looked like a typical ribbon synapse with one central element, and it was only on reconstruction that we saw multiple central elements. We found six ribbon synapse complexes with multiple central elements in our sample of 29 

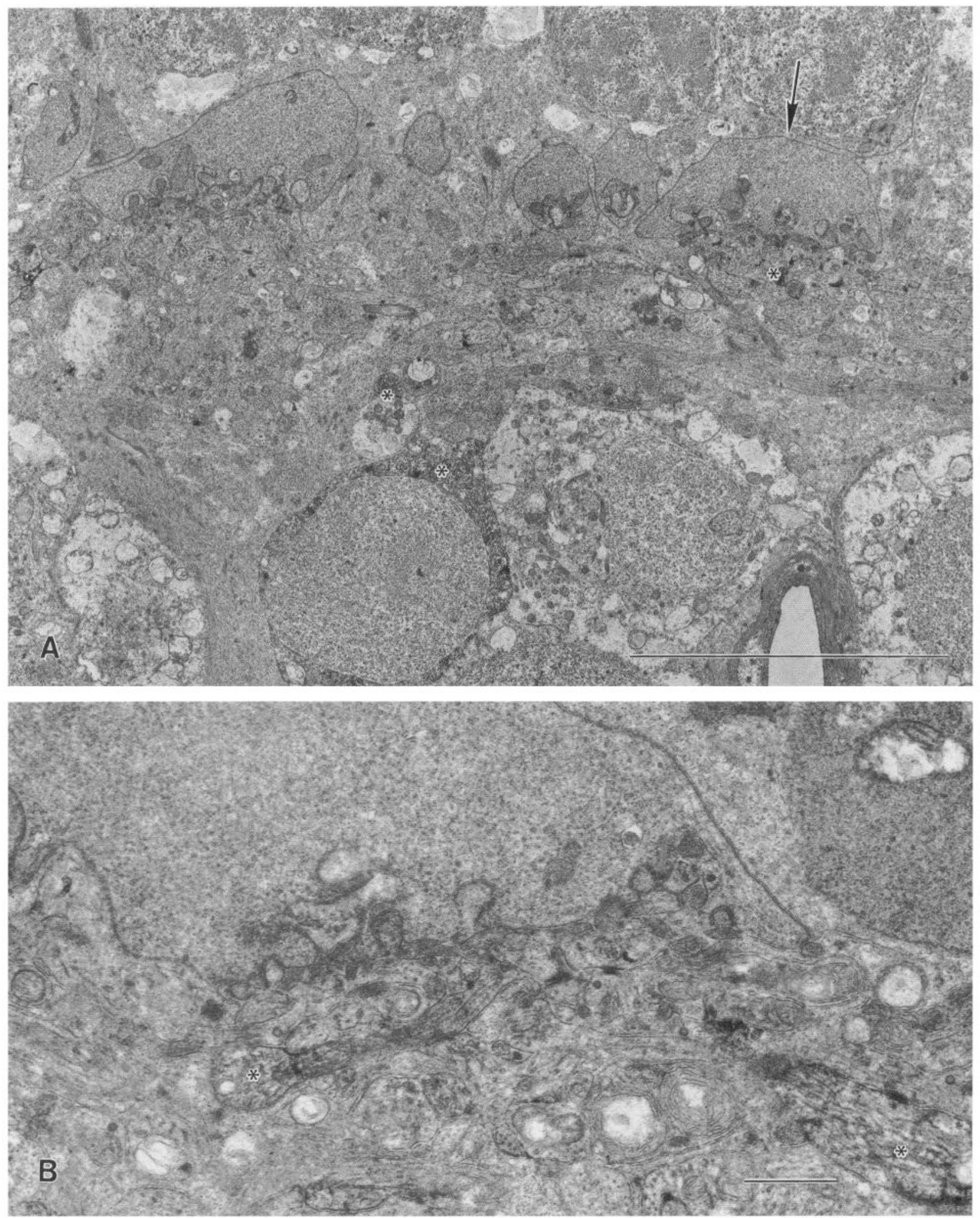

Figure 14. Electron micrographs of G6-gly-IR bipolar cell perikaryon $(A)$ and cone pedicles on which the labeled dendrites invaginated $(B)$. $A$, Low-power micrograph of the ONL, OPL, and INL showing a labeled perikaryon (asterisks) and two cone pedicles. The pedicle on right (arrow) was invaginated by the labeled dendrites. $B$, Micrograph of the OPL showing two labeled processes (asterisks) approaching a presumptive blue cone pedicle. One of the labeled processes has a diameter nearly $1 \mu \mathrm{m}$, but bifurcates further before reaching the pedicle. Scale bars: $A$, $10 \mu \mathrm{m}$; $B, 1 \mu \mathrm{m}$. 

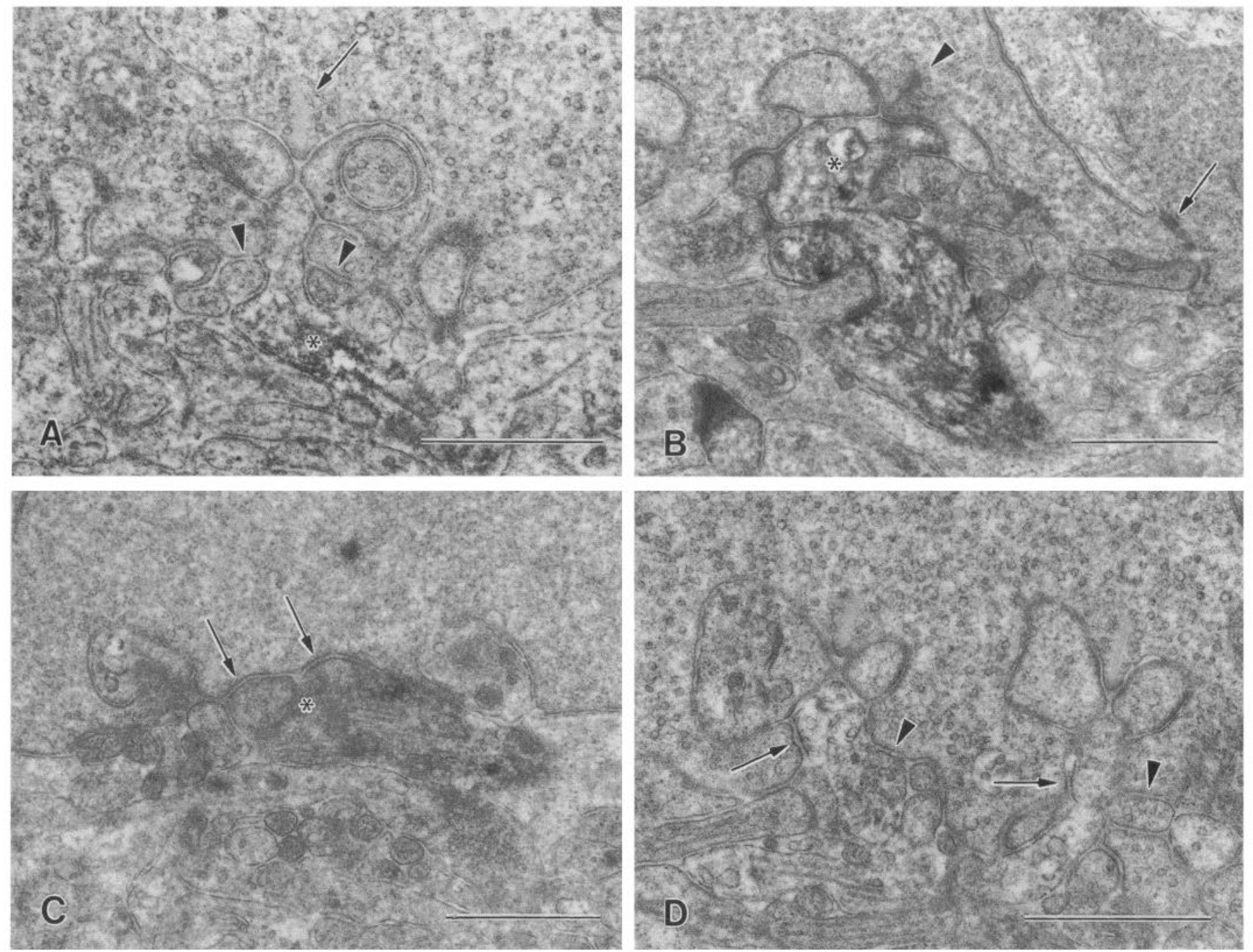

Figure 15. Electron micrographs of G6-gly-IR bipolar cell dendritic processes $(A-C)$ and synaptic structures of presumptive blue cone pedicles $(D)$. The pedicles that were presynaptic to the labeled bipolar cell dendrites were presumed to be from blue cones on the basis of the LM doublelabel experiments. A, Typical ribbon synaptic contact between a labeled dendrite (asterisk) and a cone pedicle. The labeled process is the central element of a ribbon synapse. An arrowhead indicates a triad-associated flat contact onto an unlabeled bipolar cell dendrite. $B$, Representative section through a "multi-ribbon synaptic contact." The labeled dendritic process (asterisk) had a large diameter; one synaptic ribbon it contacted is indicated with an arrowhead. This labeled process was central element of three other ribbon synapses in adjacent sections. The arrow indicates a telodendritic contact with a rod. $C$, A basal junction (arrows) was formed by a labeled dendrite (asterisk) at the base of the cone pedicle. The same process also made ribbon synaptic contacts with this pedicle, shown in $A$ and $C$. This is the only instance we observed; see the text for a discussion. $D$, Narrow-cleft junctions (arrows) between the presumptive blue cone pedicle and unlabeled central elements. The triad-associated flat contacts (arrowheads) with unlabeled processes are also seen adjoining the ribbon synapses. Scale bars, $15 \mu \mathrm{m}$.

ribbons. They might be more common, however, since synapses like these could have been misclassified as conventional ribbon synapses.

Other junctions. One contact resembling a basal junction was found between a labeled bipolar cell process and the cone pedicle base (Fig. 15C). The cytoplasmic membranes were thickened, and opaque materials were observed in the intercellular cleft at this contact. On the basis of the $18 \mathrm{~nm}$ width of this contact, it was probably an aberrant narrow-cleft junction (Lasansky, 1972; Mariani, 1984a). Furthermore, this labeled dendrite also formed the central element of a multiribbon synapse nearby (not shown). Similar basal junctions with unlabeled processes, presumably belonging to other bipolar cells, were observed on every blue cone pedicle containing labeled processes (double arrowheads in Fig. $17 B, E)$.
Fine structure of blue cone pedicles. The double-labeling study indicated that the pedicles contacted by labeled bipolar cell dendrites were almost certainly those of blue cones, and thus, other synaptic contacts of blue cone pedicles identified this way could be studied. The putative blue cone pedicles made ribbon synapses with unlabeled central elements in addition to the contacts with labeled processes as described above. In one blue cone pedicle we were able to reconstruct completely, 8 ribbon synapses had labeled central elements and 22 ribbon synapses had unlabeled central elements of unknown origin. Due to the considerable underlabeling, the absence of labeling in the processes does not necessarily indicate that these were a different type. The narrow-cleft junctions between the central elements and the pedicle membranes were more readily identifiable when the central elements were not labeled (Fig. 15D) since it was 


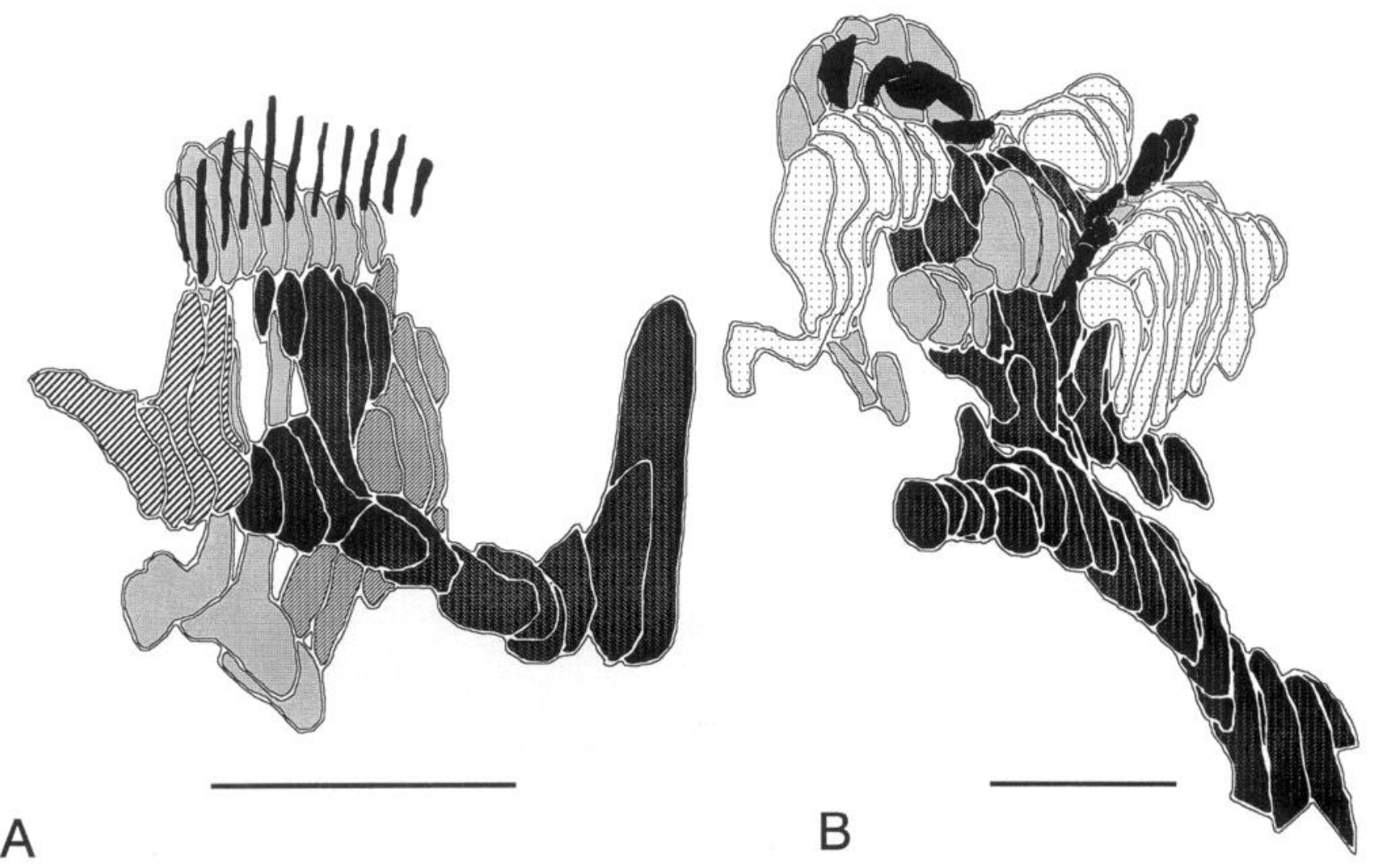

Figure 16. Three-dimensional reconstructions of synaptic contacts onto G6-gly-IR bipolar cell dendrites. Ribbons are represented in black, central elements with hatching, and lateral elements with dots. A, A ribbon synaptic contact with multiple central elements. This ribbon had three different bipolar cell dendrites as central elements. Although there were two horizontal cell dendrites as lateral elements on either side of the ribbon, only one is shown for the sake of clarity. Only one central element (darkest hatching at center) was labeled. Electron micrographs of this ribbon synaptic complex are shown in Figure 17. B, A labeled process contact with multiple ribbons. This labeled process was the central element at three ribbon synapses. Each ribbon had two horizontal cell dendrites as the lateral elements, one on each side. Scale bars, $1 \mu \mathrm{m}$.

possible to observe the thickening of both the apposing membranes and fluffy materials filling the intercellular space. Otherwise, there were no apparent ultrastructural differences between the labeled and unlabeled central elements. As mentioned above, the putative blue cone pedicles also formed numerous basal junctions in which prominent densities of the cytoplasmic membranes and opaque material or a periodicity in the intercellular cleft were observed (double arrowheads in Fig. 17B,E). Except for the one ambiguous case described above (Fig. 15C), the postsynaptic elements at basal junctions were not labeled. Such junctions are typical of flat, diffuse bipolar cell contacts (Boycott and Dowling, 1969; Kolb, 1970; Lasansky, 1972).

Each triad ribbon synapse of the putative blue cone pedicles usually had an associated flat contact. These were formed by processes that encircled the central elements at the opening of the invagination (arrows in Fig. 15D and double arrows in Fig. $17 A, D)$ and were ultrastructurally similar to those found at the other areas of pedicle base. Since the processes forming these junctions were never labeled, they almost certainly originate from other types of bipolar cells. Flat midget bipolar cells are likely candidates since they are the only types of bipolar cells known to form triad-associated flat contacts (Kolb et al., 1969; Kolb, 1970). The reconstructed pedicle also had at least three telodendrial contacts with neighboring rod spherules (Fig. 15A) with desmosome-like structures resembling those accompanying gap junctions (Raviola and Gilula, 1973; Ahnelt et al., 1990).
In this material fixed for immunocytochemistry and sectioned vertically, the cytoplasmic electron density and organelles of putative blue cones looked similar to those of other cones (Fig. $14 A, B)$. The synaptic invaginations tended to be slightly deeper in some blue cone pedicles than in the red or green types, and the ribbons also appeared somewhat more irregularly arranged in these cone pedicles. These features were likely to result from the more elaborate ribbon synaptic complexes contained in these putative blue cone pedicles.

\section{Discussion}

Morphology of G6-gly-IR bipolar cells

G6-gly-IR bipolar cells were similar in morphology to "blue cone bipolar cells" described previously using the Golgi method (Mariani, 1984a,b; Rodieck, 1988). Mariani (1984b) described bipolar cells with several primary dendrites that converged onto one or more cone pedicles and had fewer dendritic terminals than midget bipolar cells. Two other features of "blue cone bipolar cells" were that they had dendritic clusters at some distance from the axis of the cell body and axons ramifying in the fifth stratum of the IPL. These bipolar cell dendrites contacted a subpopulation of widely spaced cone pedicles, and based on his observation that the spacing of these cone pedicles corresponded to that of the blue cones, Mariani speculated that this subtype of bipolar cell selectively contacted blue cones. Analyzing the same cells stained by the Golgi method with a 

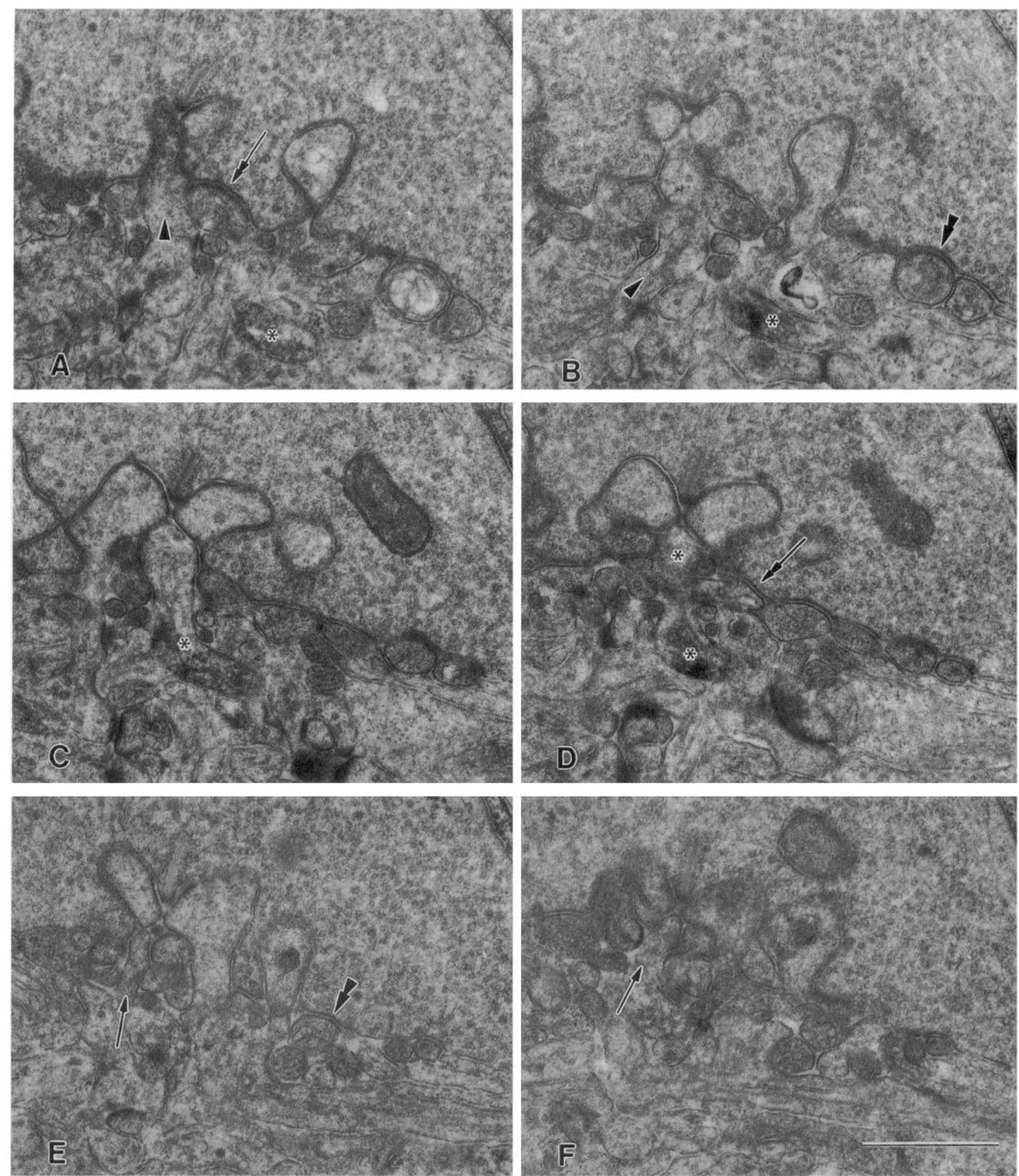

Figure 17. Electron micrographs of a series of sections through the ribbon synaptic complex with three central elements shown in Figure $16 \mathrm{~A}$. The ribbon in $A-F$ appeared in 11 consecutive sections and had three central elements (asterisk, arrow, and arrowhead). Only one of them (asterisk) was labeled, but there were no apparent ultrastructural differences between the labeled and unlabeled processes. The double arrow in $A$ indicates a triad-associated flat contact onto an unlabeled bipolar cell process. Basal junctions on the bottom surface of this pedicle onto the process of, presumably, flat diffuse bipolar cells are also seen (double arrowheads in $B$ and $E$ ). Scale bar, $1 \mu \mathrm{m}$. 
scatter diagram of dendritic field area as a function of axonal arbor area, Rodieck (1988) added the observation that "blue cone bipolar cells" formed a group distinct from that of midget bipolar cells on this criterion too. He showed that "blue cone bipolar cells" had larger axonal arbor areas than the midget bipolar cells, even when their dendritic fields were identical.

The bipolar cells labeled with G6-gly antisera had all these morphological characteristics, and we have demonstrated directly by double staining methodology that this subtype of bipolar cell selectively contacts blue cones. Although the axonal arbors of G6-gly-IR bipolar cells seem to be finer than those of Golgi-impregnated blue cone bipolars, this could be attributed to a difference in the labeling methods. Since the G6-gly antisera labeled only this single subtype of bipolar cell, we could identify them with more confidence than in Golgi preparations, even when they superficially resembled other types of bipolar cells. Thus, we were able to describe the morphological variation as well as the spatial distribution of the population.

Mariani's description of bipolar cells was quite accurate for the majority of these bipolar cells in mid-peripheral retina. There were, however, some G6-gly-IR bipolar cells that had one primary dendrite that contacted a single cone pedicle, even in the mid periphery. These cells superficially resemble midget bipolar cells (Polyak, 1941; Boycott and Dowling, 1969), and like invaginating midget bipolar cells, G6-gly-IR bipolar cells form central elements of ribbon synapses in blue cone pedicles (Kolb, 1970). However, the two types differ in many important respects. The axons of G6-gly-IR bipolar cells ramify in stratum 5 of the IPL, where their arbors range 5 to $35 \mu \mathrm{m}$ in length (see also Mariani, 1984b; Rodieck, 1988). Invaginating midget bipolar cells end more distally in the fourth stratum and form more compact terminal specializations (reviewed by Wässle and Boycott, 1991). Even when the primary dendrites of G6-gly-IR bipolar cells did not have the characteristic oblique course in the OPL, they could be distinguished by their clusters of dendritic terminals, which were less dense than those of invaginating midget bipolar cells (Polyak, 1941; Boycott and Dowling, 1969; Kolb, 1970). Differences between the two types were also observed at the EM level. Typical midget bipolar cells typically occupy approximately $90 \%$ of the central positions at ribbon synapses (Kolb, 1970; Boycott and Hopkins, 1991). In a completely reconstructed putative blue cone pedicle, however, only 8 ribbons out of 30 , or $27 \%$, had G6-gly-IR central elements. Although there were probably bipolar cells of the same type that were unlabeled due to the low yield of EM immunohistochemistry, this is not likely to account for a threefold difference in the density of terminals. Mariani (1984b) reported that his Golgi-impregnated blue cone bipolar cells occupied 8 and 11 central elements out of 11 and 15 ribbons, respectively. Our data showed comparable numbers of labeled central elements, but more ribbons in putative blue cone pedicles. We saw roughly the same number of ribbons in putative blue cone pedicles as Ahnelt et al. (1990) reported. In conclusion, we agree with Mariani (1984b) and Rodieck (1988) that the G6-gly-IR bipolar cells are distinct from invaginating midget bipolar cells.

There was no indication of different subtypes of G6-gly-IR bipolar cells. Although there were some morphological differences between the center and the periphery, there was a gradual transition with eccentricity, as shown in Figures 5-7. If there were distinct types in central and peripheral retina, some discontinuity in these parameters might be expected. Other fea-
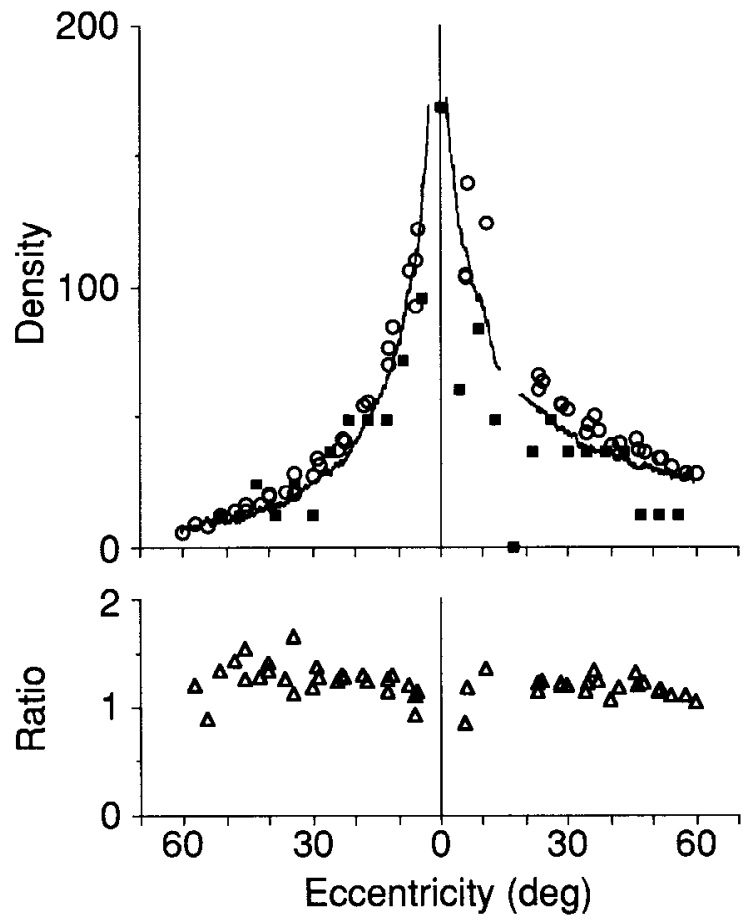

Figure 18. Comparison of the density distribution of labeled bipolar cells (circles: showing all points in Fig. 7) and that of blue cones in units of cells per square degree (line, Procion black-labeled blue cones taken from de Monasterio et al., 1985; solid squares, blue opsin-immunoreactive blue cones modified from Wikler and Rakic, 1990). Ratios of G6-gly-IR bipolar cells to blue cones calculated using the data of de Monasterio et al. (1985) are shown in the lower graph (triangles).

tures, such as the depth of the perikarya and the level of the axonal terminations, were unchanged with eccentricity. Another compelling argument that all the G6-gly-IR bipolar cells were a single subtype was that their dendrites contacted blue cones exclusively. Although there were some labeled bipolar cells that had no blue cone contacts, there was no indication that they contacted any other cones. As shown in Figure 13, the labeled bipolar cells without blue cone contacts were most numerous in areas in which blue cones were apparently missing. Several lines of evidence indicate that blue cones are more vulnerable to metabolic insult than the red or green cones (Zrenner, 1983; Sperling, 1991). Therefore, it seems quite likely that these bipolar cells had been connected with blue cones at one time but lost their connections when the blue cones degenerated. Thus, we interpret the slight differences we saw as regional variation within a single subpopulation of bipolar cells.

Fine structure of blue cone bipolar cell synapses

G6-gly-IR bipolar cell dendrites formed the central elements of ribbon synapses, as Mariani (1984b) described for his Golgistained "blue cone bipolar cells." All ribbon synapses in primate cones are thought to consist of one ribbon, two lateral elements originating from horizontal cells, and one central element from a bipolar cell. A set of bipolar cell dendrites always accompanies these processes, making triad-associated flat contacts (Boycott and Dowling, 1969; Kolb et al., 1969; Kolb, 1970; reviewed by Mariani, 1984a; Rodicck, 1988; Boycott and Hopkins, 1991). In the pedicles with invaginated G6-gly-IR dendrites, presumably those of blue cones, we frequently saw typical ribbon syn- 
apses like these, but we also found a considerable number of other types of ribbon contacts.

One of these atypical ribbon synapses is shown in Figures $16 A$ and 17 . It is called a "multi-central element ribbon synapse" in this article since two or more central elements were present at an otherwise typical ribbon synapse. This type of ribbon synapse has also been described recently by Boycott and Hopkins (1991), who found this type of ribbon synapse in one cone pedicle contacted by an invaginating midget bipolar cell. According to Mariani (1984b), the blue cone bipolar cell never contacted the same pedicle as an invaginating midget bipolar cell. Taken together, these observations would suggest that Boycott and Hopkins found a multi-central element ribhon synapse in a red or green cone pedicle. Ahnelt et al. (1990) described a variant ribbon synapse in putative blue cones of human retina that had a long ribbon associated with two or three triads. This is similar in some respects to our multi-central element ribbon synapse, except that ours had only one pair of lateral elements. Ribbon synapses with multiple central elements are quite common in teleost retinas (Scholes, 1975), where there is evidence that each process originates from a different type of bipolar cell (see Saito, 1987, for a review). Like Boycott and Hopkins (1991), however, we found no morphological differences between the central elements related to one ribbon, either in their dimensions, in their ultrastructure, or in their positions relative to the ribbon. Thus, we suggest that all the central elements at synapses like these have the same function in primates.

Another type of atypical ribbon synapse is shown in Figures $15 B$ and $16 B$. A single large central element is related to two or more ribbons, a configuration called a "multiple ribbon synapse" in this article. Similar configurations have been seen in goldfish and turtle retinas (Stell, 1967; Lasansky, 1969). In these retinas, however, ribbon synapses share not only the single central element but also lateral elements. In contrast, we saw that ribbon synaptic complexes were more discrete in blue cones of the macaque. Each ribbon typically had its own complement of lateral elements while sharing a single, large central element. This is the first description of ribbon synapses of this type in a primate retina.

In our LM double-labeling study, we showed that all G6-glyIR bipolar cell dendrites contacted blue cone pedicles or else formed "blind dendrites" that did not contact any cones. We showed by electron microscopy that all labeled dendrites within $1 \mu \mathrm{m}$ of pedicle contributed to a ribbon synaptic complex. Taken together, these findings indicate that the pedicles we studied were almost certainly those of the blue cones. Recently, Ahnelt et al. (1990) proposed several morphological criteria to distinguish blue cone pedicles from those of red or green cones based on horizontal sections of human retina. Complete, quantitative reconstructions of each cone pedicle that we studied would have been required to apply their criteria to our putative blue cones. Furthermore, we did not study our blue cones in the same plane of section as Ahnelt and coauthors (1990). Our observations qualitatively agree with the description of presumptive blue cones in vertical sections by Dickinson-Nelson and Nelson (1980). As the latter authors noted, we found that the indentations at the bases of putative blue cones were often larger than at other pedicles. Perhaps these deeper invaginations are required for the "multiple ribbon synapses" we observed. However, we saw a number of intermediate forms of pedicles, and further quantitative study will be necessary before blue cone pedicles can be unequivocally identified in vertical sections.
Functions of G6-gly-IR bipolar cells

There was no indication of input to G6-gly-IR bipolar cells from red or green cones since all complete dendrites of the G6-glyIR bipolar cells contacted blue cones. The rare "blind dendrites" did not reach the level of the cone pedicles, and in our doublelabeled material, they appeared to be most common in areas without blue cones. Two morphological observations suggest that the G6-gly-IR bipolar cells are likely to be the ON-center type. The first is that the G6-gly-IR bipolar cell dendrites are invaginating, forming the central clements of ribbon synapses, like ON-center invaginating bipolar cells in other species (Stell et al., 1977; reviewed by Wassle and Boycott, 1991). The second is that the G6-gly-IR bipolar cells have axons ramifying in the innermost stratum of the IPL, where ON-center signals are known to be processed by ganglion cells (Famiglietti and Kolb, 1976; Famiglietti et al., 1977; Nelson et al., 1978; reviewed by Kolb and Lipetz, 1991). There is, however, evidence from studies using intracellular injection techniques that this simple scheme correlating synaptic ultrastructure and the level of ramification in the IPL with the polarity of light responses may not always hold (Nelson and Kolb, 1983; reviewed by Saito, 1987; Wassle and Boycott, 1991).

The axonal processes of G6-gly-IR bipolar cells have synaptic contacts in the fifth stratum of the IPL, and approximately half the postsynaptic elements were ganglion cells and half were amacrine cells in these synapses as we previously reported (Marshak, 1989; Marshak et al., 1990). Although their axonal arbors are larger than those of midget bipolar cells (Rodieck, 1988), they are apparently smaller than their dendritic fields, and they do not completely cover the IPL. These axonal arborizations in the IPL were located more proximal than those of invaginating midget bipolar cells, but more distal than those of rod bipolar cells (see review by Wassle and Boycott, 1991).

G6-gly-IR bipolar cells outnumber blue cones everywhere in the retina. Figure 18 compares the populations of G6-gly-IR bipolar cells (modified from Fig. 7) and blue cones (modified from de Monasterio et al., 1985, and Wikler and Rakic, 1990). The ratio of G6-gly-IR labeled bipolar cells to blue cones was nearly constant at all eccentricities, approximately $1.2: 1$ (Fig. 18 , triangles). This ratio was similar to that obtained in our double-labeling experiments, where it was 1.4 . The most likely explanation for the slight discrepancy is that, while blue cones appear to be lost with age, G6-gly-IR bipolar cells seem to survive, as suggested by the labeled bipolar cells without blue cone contacts (Fig. 13). We cannot estimate the original ratio of bipolar cells to cones because no data are available on agerelated loss of blue cones in macaques. As shown in our study of double-labeled retinas, there was divergence as well as convergence in the synaptic connections between blue cones and G6-gly-IR bipolar cells. Thus, the relation between blue cones and bipolar cells is not one to one as seen between red or green cones and midget bipolar cells. There is apparently a certain degree of lateral spread of signals in the blue pathway not seen with the red or green midget systems. The acuity of the blue system would probably not be impaired, however, since there are more bipolar cells than blue cones in the array.

\section{Pathways for short-wavelength information}

It is likely that there is at least one other type of invaginating bipolar cell in the blue cone pathway in addition to the G6-glyIR type. As mentioned above, there are a number of unoccupied 
positions for central elements in putative blue cone pedicles. We found that $27 \%$ of the central elements of blue cones were occupied by G6-gly-IR bipolar cells, and due to the underlabeling, there were probably more. Thus, there would probably not be sufficient space for terminals of typical invaginating midget bipolar cells that occupy nearly $90 \%$ of the central positions of the ribbons of one cone, but there might be sufficient space for invaginating midget bipolar cells that contact two or more cones (Boycott and Hopkins, 1991). The invaginating diffuse bipolar cells (Polyak, 1941; Mariani, 1981) and the giant bistratified bipolar cells (Mariani, 1983) might also contact blue cones.

We found numerous unlabeled basal junctions similar to those of flat diffuse bipolar cells (Boycott and Dowling, 1969; Kolb, 1970), as well as triad-associated flat contacts similar to those of flat midget bipolar cells (Kolb et al., 1969; Kolb, 1970) onto the putative blue cone pedicles. Contacts like these suggest that there are other types of bipolar cells that might mediate OFFcenter responses to short-wavelength stimuli (Famiglietti and Kolb, 1976; Stell et al., 1977; Mariani, 1984a). Several investigators have questioned the existence of an OFF-center pathway in the blue system based on studies of the electroretinogram (Evers and Gouras, 1986) or of retinal ganglion cell responses (Malpeli and Schiller, 1978; de Monasterio, 1979; Zrenner and Gouras, 1981; reviewed by Gouras and Evers, 1985; Kolb and Lipetz, 1991). Recent psychophysical experiments using APB to block the ON system, however, have suggested that there are also OFF bipolar cells in the short-wavelength system (Smith et al., 1989). Furthermore, some ganglion cells have been reported to receive OFF-center blue input (de Monasterio and Gouras, 1975; revicwed by Kaplan et al., 1990; Gouras, 1991), and a few OFF-center blue-sensitive neurons are found in the parvocellular layers of the LGN (Gouras, 1991). Our observation of flat contacts by unlabeled bipolar cell dendrites onto putative blue cone pedicles suggests there is a blue OFF-center system. Further studies will be needed to determine how many types of bipolar cells other than the G6-gly-IR type contact blue cones.

\section{References}

Ahnelt P, Keri C, Kolb H (1990) Identification of pedicles of putative bluc-sensitive cones in the human retina. J Comp Neurol 293:39-53.

Ahnelt PK, Kolb H, Pflug R (1987) Identification of a subtype of cone photoreceptor, likely to be blue sensitive, in the human retina. J Comp Neurol 255:18-34.

Boycott BB, Dowling JE (1969) Organization of the primate retina: light microscopy. Philos Trans R Soc Lond [Biol] 255:109-184.

Boycott BB, Hopkins JM (1991) Cone bipolar cells and cone synapses in the primate retina. Visual Neurosci 7:49-60.

de Monasterio FM (1979) Asymmetry of On- and Off-pathways of blue-sensitive cones of the retina of macaques. Brain Res 166:39-48.

de Monasterio FM (1984) Electrophysiology of color vision. I. Cellular level. In: Colour vision deficiencies, VII (Verriest G, ed), pp 9-29. The Hague: Dr. W. Junk.

de Monasterio FM, Gouras R (1975) Functional properties of ganglion cells of the rhesus monkey retina. J Physiol (Lond) 251:167-195.

de Monasterio FM, Mariani AP (1985) Blue sensitive pathways with different spatial resolution in primate retina. Invest Ophthalmol Vis Sci [Suppl] 26:194.

de Monasterio FM, Schein SJ, McCrane EP (1981) Staining of bluesensitive cones of the macaque retina by a fluorescent dye. Science 213:1278-1281.

de Monasterio FM, McCrane EP, Newlander JK, Schein SJ (1985) Density profile of blue-sensitive cones along the horizontal meridian of macaque retina. Invest Ophthalmol Vis Sci 26:289-302.

Dickinson-Nelson A, Nelson RF (1980) Regional variations in inter- receptor contacts in primate retina. Invest Ophthalmol Vis Sci [Suppl] 19:71.

Dowling JE, Boycott BB (1966) Organization of the primate retina: electron microscopy. Proc R Soc Lond [Biol] 166:80-111.

Eldred WD, Zucker C, Karten HJ, Yazulla S (1983) Comparison of fixation and penetration enhancement techniques for use in ultrastructural immunocytochemistry. J Histochem Cytochem 31:285292.

Evers HU, Gouras P (1986) Three cone mechanisms in the primate electroretinogram: two with, one without OFF-center bipolar responses. Vision Res 26:245-254.

Famiglietti EV Jr (1981) Functional architecture of cone bipolar cells in mammalian retina. Vision Res 21:1559-1563.

Famiglietti EV Jr, Kolb H (1976) Structural basis for ON- and OFFcenter responses in retinal ganglion cells. Science 194:193-195.

Famiglietti EV Jr, Kaneko A, Tachibana M (1977) Neuronal architecture of on and off pathways to ganglion cells in carp retina. Science 198:1267-1269.

Gouras P (1991) Precortical physiology of colour vision. In: Vision and visual dysfunction, VI, The perception of colour (Gouras P, ed), pp 163-178. Boca Raton, FL: CRC.

Gouras P, Evers HU (1985) The neurocircuitry of primate retina. In: Neurocircuitry of the retina, a Cajal memorial (Gallego A, Gouras P, eds), pp 233-244. New York: Elsevier.

Kaplan E, Lee BB, Shapley RM (1990) New views of primate retinal function. In: Progress in retinal research, Vol 9 (Osborne NN, Chader GJ, eds), pp 273-336. Oxford: Pergamon.

Kita S (1984) Wide field serial sections for electron microscopy (in Japancse). Pathol Clin Mcd 2:1115-1119.

Kolb H (1970) Organization of the outer plexiform layer of the primate retina: electron microscopy of Golgi-impregnated cells. Philos Trans R Soc Lond [Biol] 258:261-283.

Kolb H, Lipetz LE (1991) The anatomical basis for color vision in the vertebrate retina. In: Vision and visual dysfunction, VI, The perception of colour (Gouras P, ed), pp 128-145. Boca Raton, FL: CRC.

Kolb H, Boycott BB, Dowling JE (1969) A second type of midget bipolar cell in the primate retina. Philos Trans R Soc Lond [Biol] 255:177-184.

Kouyama N, Hashimoto Y (1989) Photoreceptor-horizontal cell synaptic connections in teleost retina: electron microscopical survey of Lucifer yellow-HRP double marking. Neurosci Res [Suppl] 10:\$89S100.

Kouyama N, Marshak D (1989) Peptidergic bipolar cells selectively contact blue cones in the macaque monkey retina. Invest Ophthalmol Vis Sci [Suppl] 31:37.

Lasansky A (1969) Basal junctions at synaptic endings of turtle visual cells. J Cell Biol 40:577-581.

Lasansky A (1972) Cell junctions at the outer synaptic layer of the retina. Invest Ophthalmol Vis Sci 11:265-275.

Malpeli JG, Schiller PH (1978) Lack of blue OFF-center cells in the visual system of the monkey. Brain Res 141:385-389.

Marc RE (1982) Chromatic organization of the retina. In: Cell biology of the eye (McDevitt DS, ed), pp 435-473. New York: Academic.

Marc RE, Sperling HG (1977) Chromatic organization of primate cones. Science 196:454-456.

Mariani AP (1981) A diffuse, invaginating cone bipolar cell in primate retina. J Comp Neurol 197:661-671.

Mariani AP (1983) Giant bistratified bipolar cells in monkey retina. Anat Rec 206:215-220.

Mariani AP (1984a) The neuronal organization of the outer plexiform layer of the primate retina. Int Rev Cytol 86:285-320.

Mariani AP (1984b) Bipolar cells in monkey retina selective for the cones likely to be blue-sensitive. Nature 308:184-186.

Marshak DW (1989) Peptidergic neurons of the macaque monkey retina. Neurosci Res [Suppl] 10:S117-S130.

Marshak DW, Aldrich LB, Del-Valle J, Yamada T (1990) Localization of immunoreactive cholecystokinin precursor to amacrine cells and bipolar cells of the macaque monkey retina. J Neurosci 10:30453055.

Massey SC (1990) Cell types using glutamate as a neurotransmitter in the vertebrate retina. In: Progress in retinal research, Vol 9 (Osborne NN, Chader G, eds), pp 399-425. London: Pergamon.

McCrane EP, de Monasterio FM, Schein S.J, Caruso RC (1983) Nonfluorescent dye staining of primate blue cones. Invest Ophthalmol Vis Sci 24:1449-1455. 
Nelson R, Kolb H (1983) Synaptic patterns and response properties of bipolar and ganglion cells in the cat retina. Vision Res 23:11831195.

Nelson R, Famiglietti EV Jr, Kolb H (1978) Intracellular staining reveals different levels of stratification for on- and off-center ganglion cells in cat retina. J Neurophysiol 41:472-483.

Polyak SL (1941) The retina. Chicago: University of Chicago.

Raviola E, Gilula NB (1973) Gap junctions between photoreceptor cells in the vertebrate retina. Proc Natl Acad Sci USA 70:1677-1681.

Raviola E, Gilula NB (1975) Intramembrane organization of specialized contacts in the outer plexiform layer of the retina; a freezefracture study in monkeys and rabbits. J Cell Biol 65:192-222.

Rodieck RW (1988) The primate retina. In: Comparative primate biology, Vol 4, Neuroscience (Steklis HD, Erwin J, eds), pp 203-278. New York: Liss.

Saito T (1987) Physiological and morphological differences between On- and Off-center bipolar cells in the vertebrate retina. Vision Res 27:135-142.

Schnapf JL, Kraft TW, Nunn BJ, Baylor DA (1988) Spectral sensitivity of primate photoreceptors. Visual Neurosci 1:255-261.

Scholes JH (1975) Colour receptors, and their synaptic connexions, in the retina of a cyprinid fish. Philos Trans R Soc Lond [Biol] 270: 61-118.

Smith EL III, Harwerth RS, Crawford MLJ, Duncan GC (1989) Contribution of the retinal $\mathrm{ON}$ channels to scotopic and photopic spectral sensitivity. Visual Neurosci 3:225-239.

Sperling HG (1991) Vulnerability of the blue-sensitive mechanism.
In: Vision and visual dysfunction, VII, Inherited and acquired colour vision deficiencies: fundamental aspects and clinical studies (Foster DH, ed), pp 72-87. Boca Raton, FL: CRC.

Stell WK (1967) The structure and relationships of horizontal cells and photoreceptor-bipolar synaptic complexes in goldfish retina. Am J Anat 121:401-424.

Stell WK, Ishida AT, Lightfoot DO (1977) Structural basis for onand off-center responses in retinal bipolar cells. Science 198:12691271.

Szél A, Diamantstein T, Rohlich P (1988) Identification of the bluesensitive cones in the mammalian retina by anti-visual pigment antibody. J Comp Neurol 273:593-602.

Wässle H, Boycott BB (1991) Functional architecture of the mammalian retina. Physiol Rev 71:447-480.

Wikler KC, Rakic P (1990) Distribution of photoreceptor subtypes in the retina of diurnal and nocturnal primates. J Neurosci 10:33903401 .

Williams DR, MacLeod DIA, Hayhoe MM (1981a) Foveal tritanopia. Vision Res 21:1341-1356.

Williams DR, MacLeod DIA, Hayhoe MM (1981b) Punctate sensitivity of the bluc-sensitive mechanism. Vision Res 21:1357-1375.

Zrenner E (1983) Neurophysiological aspects of color vision in primates, comparative studies on simian retinal ganglion cells and the human visual system. Berlin: Springer.

Zrenner E, Gouras P (1981) Characteristics of the blue sensitive cone mechanism in primate retinal ganglion cells. Vision Res 21:16051609 